\title{
Emerging Phenomenological and Biological Principles of Consciousness: Top Insights of Prevailing Models, Concepts, and Observations
}

\author{
Ravinder Jerath*, Connor Beveridge \\ Charitable Medical Healthcare Foundation, Augusta, GA, USA \\ Email: ^Rj605r@aol.com
}

How to cite this paper: Jerath, R. and Beveridge, C. (2019) Emerging Phenomenological and Biological principles of Consciousness: Top Insights of Prevailing Models, Concepts, and Observations. World Journal of Neuroscience, 9, 157-190. https://doi.org/10.4236/wjns.2019.93011

Received: May 29, 2019

Accepted: August 3, 2019

Published: August 6, 2019

Copyright (c) 2019 by author(s) and Scientific Research Publishing Inc. This work is licensed under the Creative Commons Attribution International License (CC BY 4.0).

http://creativecommons.org/licenses/by/4.0/

\begin{abstract}
We are all aware that our experience is structured into left and right, up and down, and we can understand from our own experience that consciousness is unified into a singular whole. Although we can understand such basic phenomenological axioms of experience, there are many more principles that we cannot elucidate from our natural perspective alone. In this article, we review potential principles of consciousness revealed by prominent consciousness models, theories, and experimental observations such as the Default Space Theory, Operational Architectonics Theory, and Integrated Information Theory, which reveal biological and phenomenological foundations upon which consciousness is formed and maintained. The fundamental concepts we explore and consider worthy have largely emerged from commonalties shared by the various models which have gained attention. The concepts we review include the unity of consciousness, bioelectric operations as the substrate of consciousness, the emergence of a virtual 3D matrix, and the top-down dominance of perception.
\end{abstract}

\section{Keywords}

Default Space, Consciousness, Thalamus, Perception, Operational Architectonics, Integrated Information Theory, Neural Synchrony, World Simulation

\section{Introduction}

(Phenomenal) Consciousness as we address it is a subjective, personal experience; a type of phenomenon that seems non-physical [1], but is tightly anchored to physical-biological reality [2]. The best way to describe it for our purposes and in general is that of "pure experience" [3] [4] [5]. It may appear to 
many neuroscientists, physicists, and other thinkers that the only bigger mystery than the nature of phenomenal consciousness that exists in modern science is perhaps the origin and ultimate physical nature of the universe. The harder to solve aspect of the mystery of consciousness can be divided into two main sub-problems; what are the conditions that determine if a system is conscious, and what are the conditions that result in the many differentiated states of consciousness [6]? By determining certain axioms about phenomenal consciousness that we can be certain of from our own experience of being a conscious person, we can gain insight into and even derive further biological mechanisms that may solve easier problems of consciousness [7].

Science cannot completely penetrate many technicalities when studying consciousness due to its subjective quality, very different than the physical and mathematical realms in which it normally operates. However, when we study consciousness through the lens of our own experience in combination with scientific research, then we can truly advance towards demystifying it. In this article, we review concepts we consider principles of consciousness that have been established by various distinguished models and research. We review these concepts through the lens of the Default Space Theory which was developed in part via prolonged phenomenological observation of the structure of subjective experience [8]. It could be argued that the nature of consciousness is too complex and elusive for the current scientific community to establish any certainties about it. We suggest however that some aspects about its phenomenology are undeniable (such as that is exists [9]), and some biological explanations for its emergence are highly persuasive. We may be a great distance away from understanding how certain physical systems can give rise to consciousness; however, we can still open this frontier for exploration by understanding its basic phenomenological and biological aspects [1].

\section{The Default Space Theory}

The principles of consciousness we suggest in this article are largely components of the Default Space Theory (DST) that are shared with other prominent models. The DST is different from other popular metastable models of consciousness in that it is not brain-centric, but an embodied model that propounds consciousness emerges from the body as well as the brain [8]. The DST explains how sensory information originating from external stimuli, internal visceral stimuli, and mental generation is processed, integrated, and filled into a spatial, three dimensional, internal virtual simulation of the external world [8]. Consciousness is in a way identical to this space termed the default space, and it can be thought of as the architectural structure of consciousness. The thalamus is the center of this global bioelectric space, orchestrating the emergence of the space as an informational hub [8]. The default space provides the medium for replication of the external environment in order to provide optimal interaction within the natural physical and ecological environment [10]. In suggesting potential fundamental 
principles of consciousness, this article while will have a bias towards this theory's perspectives.

The DST is also unique in its description of the architecture of the bioelectric framework isomorphic to phenomenal mind. The stress put on the thalamus as a key component of a holistic bioelectric system helps explain some of the top mysteries of mind [11]. The DST describes this bioelectric system as a frequency-based hierarchy which includes bodily rhythms at the foundation [12]. The DST helps answer the binding problem by describing how the thalamus uses reentrancy or looping activity to coordinate and unify widespread cortical activity into a macroscopic bioelectric structure [8]. In addition, by describing the physiological nature of the $3 \mathrm{D}$ virtual matrix of consciousness, it provides a means to further explain how diverse multimodal cortical modules are unified and what biological function consciousness really emerges from (creation of an internal simulation of the world) [13]. By describing biological processes in relation to a default virtual construct, it describes how we may have a seamless experience as the current simulation of the world also provides top-down context allowing for quick integration of new information.

\section{Consciousness as a Unified Virtual Construct}

Although some early thinkers such as Jung criticized the idea [14], a common assumption in many consciousness conceptualizations is the unified and singular nature of consciousness. Although it is interesting to ponder whether multiple, separate, and phenomenologically distinct consciousnesses exist within one human being, which may be the case in split-brain syndrome [15] [16], it is commonly believed that a singular consciousness experience is attributed to any healthy person. Some neuroscientists believe that the hundreds or thousands of mesoscopic processing modules in each brain may possess its own consciousness [17]. Modern models emphasize that while although there may be multiple consciousnesses in one brain (on different levels assuming consciousness can be quantified), each phenomenal consciousness is independent and itself a unified virtual construct [7] [15]. The term virtual is used to describe a phenomenal experience for the same reason a computer-generated reality is. The nonmaterial virtual reality of a computer does not exist physically in the computer, and the same can be said of phenomenological reality not existing physically in the brain [2].

The Integrated Information Theory (IIT) proposed by Tononi posits such a unified nature of experience as self-evident, and it is one of its axioms of consciousness along with its spatial structure and irreducibility [7]. IIT is unique as it describes the substrate of phenomenological experience not only biologically, but physically, tying consciousness to any unified physical system that processes information in a certain way while also being irreducible in its repertoire of potential cause and effect relationships [7] [15]. The DST shares this common perspective of prevailing models on the biological explanation of such pheno- 
menal unity. That being consciousness is not the product of specific neural sites in the brain, but is the result of a prodigious (neuro) biological system that the DST asserts extends to the body [18] [19]. In addition to the unification of cognitive acts across diverse areas of the brain [20], if the qualia of experience are unified, there must a mechanism to unify all of the neural information isomorphic to the qualia contained in that experience [21]. The dynamic variations, synchronies, and signals of bioelectric neural oscillations may provide the medium for such phenomenal unity [1] [11] [19]. The unified and integrated phenomenal experience is thus suggested to be isomorphic to a bioelectric, unified metastable continuum (UMS) across the brain [1] [22], and potentially the body [8]. The UMS is a dynamic, hierarchical, bioelectric architecture of macroscopic level [22]. Via similar correlates, some have even suggested consciousness extends to the environment [19].

\section{Consciousness as a Simulation of the External World}

Optical illusions provide a first-person account of the true nature of consciousness, that we do not directly perceive actual reality, however, we perceive a subjective version of it. According to several models and researchers, the phenomenal reality we experience is a virtual one and may be functionally understood to emerge from or be identical to a simulation or model of the external, objective reality [2] [11] [23] [24]. This includes modeling of the self [25] [26]. The notion that a main function of the brain is to internally model the external environment and internal processes originated in the earliest days of cognitive science [27], and the founding principles of simulation theory go back to the $18^{\text {th }}$ century [28].

Modeling the external world is a crucial animalian survival mechanism [29]. As an interesting active sensing example, bat brains create three-dimensional (3D) spatial models of their environment using their own reflected sound waves [30]. Even modern robotics methods interact and understand the world by simulating the robot's environment and its relationship to it [31]. We assert that considering the contents consciousness as a recreation and not a direct perception is an undeniable reality supported by basic logic and research. Thus, the contents of consciousness can be considered a simulation.

Several of these simulation models suggest the phenomenal foundation of this simulation is a (un/sub) conscious, 3D coordinate matrix, or virtual space, in which all qualia are embedded [8] [26] [32]. This virtual space explains how the contents of consciousness are unified and integrated into one experience [2] [13] and may bridge the gap between biological systems and phenomenal consciousness [32]. It is suggested to be functionally isomorphic to certain lower-complexity (un/subconscious), electrophysiological components of a UMS [1] [32]. The DST has propounded that the ultraslow $(<0.1 \mathrm{hz})$ oscillations, which act over much larger distances [33] and neuronal groups compared to higher frequencies [34], are the component which creates the framework isomorphic to this virtual 
3D matrix [13]. It has termed this virtual space the default space as the external world is defaulted within it [8].

The Fingelkurts describe such level of brain activity isomorphic to the phenomenal structure of mind as the operational architectonics level [32]. They point to a variety of research [35] [36] [37] to suggest phenomenal consciousness arises when a certain bioelectric architecture dominated by alpha and beta oscillations is maintained [38]. They suggest however that the subconscious 3D matrix is constituted not only of networks of oscillations, but also the material networks of neuronal assemblies [32]. Although this virtual matrix is un/subconscious, via meditative practices, one may become more aware of its underlying presence [39]. The functional necessity of such a 3D matrix underlying human, if not all animalian, experience is demonstrated in contralateral neglect syndrome [32] [40] (Figure 1).

We may feel that our awareness is a firsthand experience of reality, however, it is heavily influenced by our expectations, past experiences, and biases instead of a direct experience of external stimuli [2] [24] [41] [42] [43] In this way, we experience an "informed hallucination", or best guess of the world [43]. The nature of this hallucination is revealed in first-person observations. For instance, the "blind spot", which is the area of the retina lacking photoreceptor cells where the optic nerve passes through the optic disc, reveals how capable the mind is of creating realistic perceptions [44]. When one eye is closed, the brain fills in the blind spot with surrounding visual patterns, giving the illusion of a seamless, external, and unaltered visual experience [45].

Several modern models identify consciousness with a simulation of reality, the self, and organisms-environment interaction. Revonsuo may have been the first to use a metaphor of virtual reality to describe such an internal simulation [2]. Many of the world-simulation models point to dreaming as strong evidence of the brain's ability produce its own subjective experiential reality [2] [8] [32] [46], with $90 \%$ of dreams being experienced as real within a spatially extended virtual reality [47] [48]. Nightmares likely serve as a defense mechanism to simulate dangerous situations in order to practice escaping from these situations such as running from a bear [49]. The threat-simulation theory proposed by Revonsuo formally describes such a simulation defense mechanism that leads to more efficient threat perception and avoidance [50]. Dreams thus show the functional value of simulation.

Trehub's Retinoid model attempts to describe how the brain produces such an internal model of its intimate world via a minimal neural system that combines disparate sensory stimuli into a unified representation [26]. Metzinger's Self-Model theory of Subjectivity explores how the "self" does not truly exist; however, we simulate a model of a self. Although there is a phenomenal distinction between this simulation of self and the simulation of the external world, the self is still an internal, virtual representation of our mental and physical being [25]. Philosopher and cognitive scientist Rick Grush has proposed an information-processing strategy termed the emulation theory of representation which explains how the 


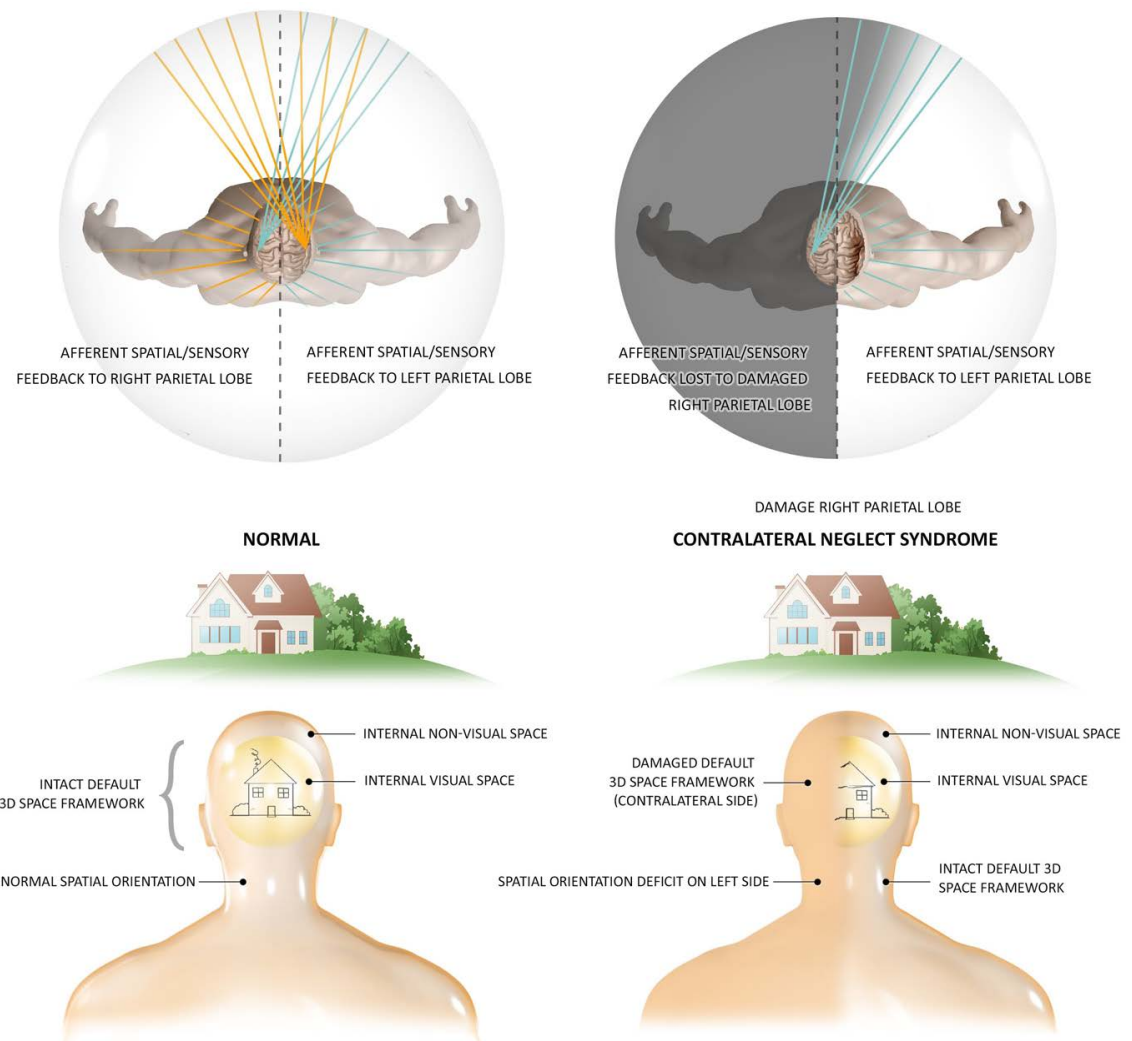

Figure 1. Contralateral Neglect Syndrome and a 3D Virtual Space. Contralateral neglect syndrome often occurs due to damage of the right parietal lobe which maps spatial information to perceptions. The left parietal lobe maps only the right side of the perspective. Even though the undamaged, left afferent stream is fed to the damaged right cortex in those with contralateral neglect syndrome, these sensations cannot be spatially oriented and therefore cannot be experienced. This syndrome suggests that a subconscious 3D matrix is the structural foundation of consciousness. These patients not only lack perception of such sensation, but the entire left side of space ceases to exist to their perspective. This is illustrated in the figure by the absence of the left side of perception in those with a damaged spatial framework. These patients are not aware of "missing space', and experience the intact right side as the full physical world. Even the actions of these patients can be limited to this side; they may eat from only one side of their plate or dress one side of their body. Research demonstrates that stimuli from the "missing" side is processed, but remains unconscious without integration into a spatial landscape (Figure by Lynsey Ekema, MSMI. (c) 2014 Dr. Ravinder Jerath. All rights reserved. Previously published in [11]. Permission provided by Creative Commons License).

brain produces neural circuits that model the body environment [24]. He describes mathematically how these models run in parallel with the body and environment in order to provide top-down expectations which enhance and process sensory information. This top-down nature of perception is another principle which we explore later in this article.

Robert Gordon has applied such a simulation theory to the "theory of mind", in which we can understand other's actions and perceptions through simulating them [51]. Hesslow describes how thinking and the inner world of consciousness consist of simulated interaction with the environment [23]. He identifies 
the simulated inner world as an evolutionary fundamental function of the brain and uses the simulation hypothesis to tie together actions, perceptions, and cognitive functions, explaining why imagining activities such as playing tennis leads to the occurrence of activity in perceptual and motor neural structures that would be present [52] if one was actually playing tennis [23]. We suggest this active, internal 3D simulation is the central cognitive, perceptual, and behavioral framework of mind in potentially all animals. The default mode network (DMN) may play a direct role in the maintenance such a simulation [39] [53]. The high levels of energy that would be required to continually maintain such a simulation may provide an explanation for why DMN and other intrinsic brain activities utilize $\sim 90 \%$ of the brain's energy [54] [55].

\section{The Thalamus as a Central Hub}

Based on significant research [56] [57] [58], the thalamus, via its hub role in the thalamocortical system, has been described by prevailing theories of consciousness as essential to consciousness [8] [59]. IIT, which proposes that consciousness arises from irreducible physical systems which integrate information in a certain manner, has described the distributed thalamocortical network as the neural substrate of consciousness [6] due to its specialization (rapid and effective interactions) in integrating information from within and among distributed cortical areas [60] [61]. This network is organized for a metastable activity, promoting both specialization of cortical sites and their integration into a greater, more abstract network [6] [62]. A theory also developed in part by Tononi, the Dynamic Core Hypothesis (DCH), describes a unified, dynamic, widespread, information integrating system or "core" as the correlate of consciousness composed of synchronous, reentrant activity among interconnected corticortical and corticothalamic networks [63] [64]. The GWT also identifies the corticothalamic system as the candidate for a substrate of unified consciousness or "workspace" which allows for a globally functional system of bidirectional signaling, binding information from independent, unconscious modules [65].

The thalamic hub includes about fifty nuclei that connect the sensory organs with respective cortical projections [66]. The thalamus is also suggested as a hub of consciousness due to its coordination and rich reentrant connectivity throughout the cortex [8] [59] which may allow for large-scale oscillatory harmony necessary for an integrated experience [32]. It is like the conductor of a vast bioelectric orchestra of mind. According to the DST and other metastable models just mentioned, the thalamus is the main integrator of global information, coordinating a global oscillatory framework largely through corticothalamic feedback loops [8]. The thalamus is the medium through which the cortex "talks to itself" [67], allowing any cortical array to signal any other [68]. In this way, the thalamus is the central server in a "World-Wide-Web" of the cortex in which any cortical site can contact any other [65] [69].

Baars ties this "any-to-any" broadcasting to the binding of sensory percep- 
tions into a unified whole, and identifies activity which broadcasts globally as the activity rising to consciousness; therefore, no single corticothalamic location is privileged to consciousness [65]. Clearly, however, the thalamus is privileged to consciousness as it is required for the essential thalamocortical-corticothalamic network to exist. Dehaene and Changeux have extended Baars global workspace theory into a more neural implementation termed the global neuronal workspace [70]. They describe how the thalamus allows for global activity patterns among multiple brain systems that create a meta neural network leading to consciousness [71].

In similarity to the DST, Ward discusses in his thalamic dynamic core theory that although the cortex computes the contents of perception, the thalamus is responsible for "displaying" those contents and thus creating the perceptual experience [72]. In his view we support, experience occurs when the cortex "informs" or synchronizes with the respective thalamic nuclei its activity which is integrated into the thalamic dynamic core or unified metastable continuum and thus its isomorphic, phenomenal counterpart, the default space of the DST [8]. The thalamic dynamic system described by Ward and by the DST consist of bioelectric neural (and non-neural according to the DST) synchrony, and thus such synchrony is proposed as the ultimate neural correlate of consciousness [72].

The DST asserts a much stronger role of the thalamus compared to other metastable models, with some metastable models asserting that consciousness can occur anywhere throughout the cortex with disregard to the thalamus [1] [32]. As discussed previously, the DST asserts that the unified bioelectric architecture which is the foundation of consciousness is organized, synchronized, and harmonized by the thalamus, [11], and that it "fills" in perceptual qualia generated across specialized cortical sites into the 3D virtual matrix [8] whose isomorphic counterpart is found across the brain and possibly body [13]. The DST explains how the thalamus, in a sense, "views" the entire bioelectric structure surrounding it which is supported by that fact that it represents a core, convergent, miniaturized map of the cortex and sensory organs [72].

The thalamic intralaminar nuclei project reentrant connections widely to all cortical areas, and their destruction can result in a permanent loss of consciousness [73]. Removal of other large portions of the cortex and brain however often do not significantly diminish consciousness, demonstrated by its persistence after the removal of the frontal cortex [74], hippocampus [75], cerebellum [76], and even an entire cerebral hemisphere [77]. Even removal of small portions of the thalamus can lead to significant cognitive problems [78], and thalamic deep brain simulation may restore consciousness to patients in coma and vegetative states [79]. The thalamus relays all sensory information to the cortex and contrary to prevailing views also relays olfaction [80]. In addition, it also is involved in sensory processing [81] and multi-sensory integration [82]. Most anesthetics seem to temporarily terminate consciousness via a "hyperpolarization blocking" of relay nuclei of the thalamus [83], and a similar mechanism is observed in deep sleep [84]. 
The internal template of the world in which consciousness "inhabits" parallels the physical qualities of the external world. We have proposed how spatial planes of experience such as horizontal, vertical, radial, anterior, and posterior exist respective of one's thalamus [8]. Phenomenal experience consists of a direct presence at the center of an externalized, spatially based (virtual) reality [2] [26]. We speculate this sense of the self-center exists in respect to this physical location of the thalamus because of its significance as the "center of mass" of the bioelectric architecture of the mind. Although cortical areas likely generate this sense of self and its localization [85] [86], it may virtually map this phenomenal sense of self-center to the thalamus. If one closes their eyes and tries to pinpoint the exact location of their perspective, they will find it exists slightly above and behind the eyes, which is the anatomical location of the thalamus.

The significance of a "topographic map of the self" in which the self is centered at the most relevant anatomical location may be similar to benefits produced by other topographic maps which include metabolic benefits [87], improved connectivity, reductions in neural volume [88], and possibly operational improvements or requirements to the functional bioelectric architecture producing consciousness. The placement of self-center in the head is by no means a functional or anatomical requirement. This is demonstrated by out-of-body experiences [89]. The plasticity of self-perception allows for people to adopt and control new bodies as their own through modern virtual reality technology [90]. The virtual body can be attributed by the participant as their own physical self, providing perceived agency over this virtual body as the participant further attributes its actions as their own [91]. Thus, if self-center is truly localized at the thalamus, this may suggest its anatomical and/or functional importance.

\section{An Isomorphic, Bioelectric, Metastable Architecture of Consciousness}

The DST [11] [13], Operational Architectonics Theory (OAT) [32], and others [2] [19] [59] discuss in varying perspectives an isomorphism between the unified nature of human experience and a unified, metastable, bioelectric construct consisting of functional synchronies in various hierarchic levels of complexity ultimately harmonized within a global synchrony. This architecture is sometimes referred to as a UMC, or dynamic core as mentioned previously [22] [59]. Metastability in reference to cognitive neuroscience describes the neural activity of coordinated, global integration of independent functional modules that retain their autonomy while still being a part of macro operations [92] [93] [94]. In this metastable mode of function consisting of the co-existence of independence and cooperation, information is created and then percolated throughout the various dimensions of dynamic bioelectric operations across various neural and macroscopic assemblies [95] [96]

Metastability helps solves the mystery of how diverse and distributed brain activities can give rise to a single integrated experience. Such neural activity of 
consciousness is metastable because involved brain regions perform their own innate tasks while still coordinating together to create a larger, more abstract architecture [97]. This characteristic may allow for the non-linear dynamics of global bioelectric frameworks which switch dynamically from state to state, each bioelectric state transition arising from a reconfiguration of the underlying neural network configuration [98] [99]. Metastable brain states are like winner-less competitions, each unique state being outside of natural equilibrium but only dominating global activity for a period of time (quasi-equilibrium) [100]. Each quasi-stable state when reaching the point of instability quickly shifts to other quasi-stable states during "rapid transition processes" [101]. Operating close to points of instability allows for rapid switching between states [98]. The brain at rest has been found to have to most amount of network switching between unique metastable states [102].

There are three general dimensions of bioelectric activity from microscopic to macroscopic. Macroscopic activity is suggested to be responsible for the integrated experience and can influence the micro/mesoscopic while also ultimately being composed of micro/mesoscopic activity [32] [103]. Neural and non-neural cells microscopically communicate electrical membrane potential events to adjacent cells via synaptic communications [104], electrical coupling via gap junctions [105], ephaptic coupling via local electric fields [106], and dynamic interactions of voltage-gated ion channels [107]. Mesoscopic brain dynamics occur between groups of neurons within cortical areas. They occur via synaptic and electric field interactions and lead to synchronized firing patterns that can result in synchronization of firing patterns with other cortical areas [32] [108]. This gives rise to large-amplitude oscillations which can be observed outside the scalp using electroencephalography [108]. Such interactions between distal brain areas are referred to as macroscopic oscillations which may form synchronized feedback loops that occur most often in the thalamocortical system [69]. At this level, a greater level of orderly complexity and abstraction emerges as coherence among all or many mesoscopic networks is formed [1].

The binding of mesoscopic modules unties the sensory and cognitive frameworks into a global harmony and thus allows for the integrated consciousness experience [1] [32]. The DST and OAT describe such global macroscopic oscillations as the highest level and complexity of the unified bioelectric structure responsible for the integrated experience as a harmonic amalgamation of mesoscopic and thus microscopic activity among independent modules [11] [32]. The DST extends this bioelectric architecture from only the brain as described by OAT, to the peripheral sensory organs [8] [38] [109]. Synchronous interactions temporarily occur between specialized assemblies responsible for certain perceptual qualities [110]. For instance, neural assemblies responsible for depth perception synchronize with those responsible for brightness leading to perceived changes in brightness to alter the perception of depth [32]. The integrated experience is likely formed when synchronies between various modules syn- 
chronize with other oscillatory functions leading to a more abstract and higher level order which can be global [32]. Therefore, this vast complexity of bioelectrical operations that occur at multiple levels from the basic membrane activity of the cell to global oscillations may create the physiological architecture for a "virtual" reality of consciousness with the lower levels of membrane potential activity creating the underlying unconscious fabric by providing a fundamental substrate for mesoscopic and thus macroscopic harmonic activity.

Edelman has described two types of consciousness, a basic sensory consciousness and a higher or secondary consciousness. Sensory consciousness is the primary consciousness which consists solely of sensory qualia bound to time and space without any sense of past or future [111]. This primary consciousness occurs in animals with humans additionally possessing advanced metacognition allowing us to have higher consciousness and be "conscious of being conscious" [59]. Phenomenal consciousness and its qualia intuitively seem and are referred to largely as inherently non-physical [1] [112] [113] [114] [115]. Pondering how an experience, although emerging from the material, chemical, and electrical operations of neurons could be physical leads nowhere fast [116]. Assuming that conscious experience is non-physical and that distributed bioelectric operations are isomorphic to consciousness, there arises a mystery on the nature of such "higher" or "meta" consciousness. The fact that we are cognitively aware that we are conscious strongly suggests such awareness is coded into our physical brains. Similar to other problems arising from the clash of physicalism and non-physical qualia, if the qualia of phenomenal experience are truly non-physical, then there exists an "interface" problem of how the physical system of the brain could know, understand, and be cognitively aware of something non-physical. Edelman suggests syntactical language allows for such "meta-consciousness" [59], however, this explanation is very unsatisfactory when looking at the interface problem from a physical systems perspective.

Even when external sensory stimuli cease, the experiential frameworks of the respective sensations most often remain idling in consciousness. For instance, when entering a completely lightless room, you do not cease to see, however, you see blackness. Those without such a visual framework developed over years of experience-based learning such as in the case of the congenitally blind lack any experience of visual imagery whatsoever and do not "see" darkness [117]. People born blind have no first-hand understanding of what it is like to have vision, and if they somehow acquired working retinas later in life, the brains of those congenitally blind patients would receive a flood of visual stimuli that they are not prepared to handle [118]. However, due to the brain's amazing ability to identify informational patterns and dynamic neuroplastic ability to restructure existing cortex with a different active role, those congenitally blind patients with restored vision can learn to truly see, even without a retina or occipital lobe (potentially all) [119] [120]. By mounting a camera on their shoulder and a stimulus converting, pixelated array/screen of vibrating units (each unit vibrating in in- 
tensity relative to the brightness of its pixel location in the $2 \mathrm{D}$ visual image) on their tongues or backs, their brains can learn to transform the tactile information into a visual experience [119]. Cameras can also be used to turn visual images into soundscapes which can be experienced as visual when enough practice has taken place [121].

In these successful "sensory substitution" methods, it appears that the unique organization of information in stimuli is identified and formatted into an appropriate sensory framework by the brain [122]. These insights indicate the "blueprints" for sensory frameworks lie not in their cortical locations or sensory receptor anatomy, but in an operational, bioelectric structure differentiated not only by physical signal properties of the operations among distributed assemblies, but in the information processing system they create. Depending on their metastable bioelectric architecture they produce a unique phenomenal quality from the variety of sensory modalities. Thus, any new frameworks that would be developed could be integrated into a UMC naturally by the brain, providing the potential for future neuroengineering efforts that would allow people to consciously see things like x-rays, other frequencies of the electromagnetic spectrum, or truly anything which could be sensed with a device and transduced into equivalent neural activity. This could be implemented by the "sensory substitution" described (camera-to-tongue) [119] or perhaps by direct input to the appropriate thalamic nuclei.

\section{The Top-Down Domination of Perception}

We have discussed how our experience of reality is truly an "informed hallucination", a virtual simulation generated within. Furthermore, this experience is likely dominated by perceptions and predictions largely formulated within the brain [11]. Of the vast amount of sensory stimuli bombarding our many sensory organs at any given moment, an estimated $99 \%$ of the data is discarded [123]. Our brains simply do not possess the computational power to process such an immense spectrum and quantity of sensory stimuli and have it all presented to conscious awareness [124]. The DST suggests top-down predictions transported via bioelectric synchrony [60] (also the substrate of experience) dominate in generating the information embedded into the subconscious $3 \mathrm{D}$ matrix or default space [11]. By integrating cognitive predictions with incoming sensory stimuli, computational demands can be greatly decreased [60] [124].

Top-down predictions derived from current context (current state of world simulation), attention, memory, biases, past experiences, higher cognitive functions, and even genetics [125] likely modify, filter, and amplify transduced stimuli [126]. The DST asserts the externalized simulation that we experience day to day is the most crucial source of expectations (particularly expectations of the environment such as localizations of objects) which allow for near immediate integration of incoming predicted stimuli into the continually maintained world simulation [8]. Each moment of this world simulation provides a means to de- 
rive expectations about the next [11].

Mechanisms for top-down predication are vastly important in reducing surprise, uncertainty, and time and energy expenditures while facilitating interactions with external stimuli [124]. The accurate prediction of the external world from the internal template is not an genetically innate function. Experience-based mapping and development of sensory modalities to qualities and concepts of the real world (movement, occlusion, etc.) must take place before accurate predictions of the world can be integrated with incoming stimuli and experienced as such [124]. By integrating stored knowledge, current context, and higher cognitive functions with sensory input, there is an immense reduction in the necessity of considering large numbers of external causes for sensory events which enables quicker [127] and more accurate [128] conscious interpretation of such events [124].

If sensory experience were solely a bottom-up process, many ambiguous properties of a stimulus could not be resolved as often they can only be resolved by inferring properties through context derived from previous experiences [129]. Expectations are thought to originate at higher cortical sites and project to lower cortical sites as well as all the way back to the thalamus [126]. Indeed, top-down projections from higher-level cortical regions to lower-level ones are abundant, most notably in the visual and somatosensory systems [130] [131] (Figure 4). Although traditionally neglected, prodigious feedback connections exist in both systems extending to thalamus, brainstem, and even spinal cord (somatosensory), actually outnumbering feedforward connections [131] [132].

While such top-down effects may be thought of as an unconscious cognitive activity, there is indeed an intimate relationship between top-down mechanisms and consciousness. Top-down expectations increase the speed of conscious access to relevant perceptual stimuli [133] [134] and may boost otherwise unconscious stimuli into awareness [126]. This intimate connection is deepened when considering the fact that the substrate or mechanisms from which consciousness emerges as well as of top-down effect are described very similarly by prominent models, both consisting of reentrancy [135] [126], bioelectric synchrony [59] [137], and feedback [60] [138]. Information reaching conscious awareness is thought to trigger the feedback, macroscopic reentrant activity, and any-to-many "broadcasting" needed for top-down effect and which are most readily implemented by the thalamocortical system [65] [126]. Indeed, stimuli than confirm our expectations are more likely to enter awareness [126], possibly by amplifying the stimulus or by sharpening neural representations of it [139]. It is likely that active implementations of top-down predictions require conscious awareness of them [126].

In addition to academic research, numerous self-observations and neurological conditions reveal the nature of the top-down prevalence of perception. For instance, those suffering from phantom limb syndrome experience possessing a "ghost limb", or body part that once existed but was lost due to an amputation 
or accident [140]. These sensations arise from topographically organized, somatotopic maps of the body in the somatosensory cortex [140]. This condition illustrates how what we experience is not dependent on what signals are sent from the sensory receptors, but derived more so from the contents of the mind [141]. An experiment that can be performed at home, the "rubber hand illusion", further demonstrates how even the unified sense of self is a construction of the mind. In this illusion, focusing on an artificial hand being stroked synchronously with one's concealed hand leads the participant to experience the artificial hand as being their real hand [142]. Top-down phenomenona can be so intriguing that they have often become a focus of worldwide popular attention via the media. For instance, an audio clip that went viral due to top-down differences among people was perceived significantly differently to around half of listeners than to the other half depending on how their brains interpret the various frequencies in the audio based on experience and expectations [143]. Some perceived hearing the word "laurel", while others heard "yanny", and by intentionally expecting to hear one or the other, many listeners can choose which one they hear.

\section{An Organizational Hierarchy}

Hierarchy is a fundamental concept of modern theories of brain function [144]. The UMC and neural activity in general have been proposed by a variety of author's to be composed of a variety of dimensions of hierarchies [145] including the micro-to-macroscopic bioelectric hierarchy discussed and hierarchies of neural pattern recognizers [146], parallel loops, oscillators [145], anatomical layout [147], and fractal or nested network modules [109] [148] [149]. In addition to these, a frequency-based hierarchy likely exists for non-linear bioelectric activity [12]. As mentioned, we have asserted that ultra-slow frequencies of micro-to-macroscopic oscillations are a foundation for a UMC isomorphic to the virtual foundation (a 3D matrix) of consciousness [13]. This is derived from the idea that neural activity from which mind emerges (a UMC) is self-organized so that slower frequency activity underlies faster frequency activity. Modern research supports this idea that bioelectric oscillatory activities are hierarchically organized so that the signal properties of each frequency band (alpha, gamma, etc.) are modulated, entrained, locked with, and grouped by the lower frequency oscillations [34] [67] [150] [151] [152] [153] (Figure 2). We have proposed that bioelectric activity (from which mind emerges) in the form of oscillations occur in frequency-based layers and that the lower layers support activity of the higher layers [12] (Figure 3).

The most basic layer we have described consists of ultra-slow to slow, intrinsic activity of neural and non-neural activity. The non-neural activity will be discussed in the next section. The neural component consists largely of activity within the default mode network (DMN) which has an importance in supporting higher activity illustrated by the relative cost of its activity in terms of brain 


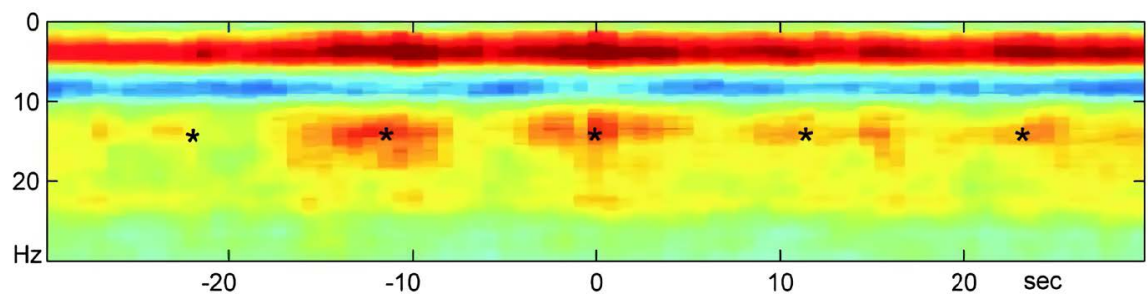

Figure 2. A Neocortical Power Spectrogram Reveals a Frequency Based Hierarchy. This figure shows a power spectrogram which represents oscillatory activity visually based on the power of each frequency on the spectrum of neural oscillations over time. The spectrogram here reveals the normalized power average of neocortical hippocampal ripples in a large set of mice. It demonstrates the hierarchical nature of frequency-based activity in which slower oscillations modulate and entrain the higher ones as well as the propensity for the slow oscillations to synchronize higher frequency among different neural areas. The *s signify hippocampal ripples which exhibit comodulation and entrainment of the neocortex and hippocampus by the underlying infra-slow activity $(0.1 \mathrm{~Hz})$. The ripple activity is modulated by the Beta activity and both are further modulated by the Delta Activity indicated by the red band. This figure further demonstrates that the hierarchy of entrainment by slower oscillations exists at multiple levels. Image reproduced from [210]; permission provided by CC-BY, Copyright 2003 National Academy of Sciences.

energy consumption [12]. The majority of brain energy consumption is attributed to this intrinsic activity [154]. The DMN being a key component of such an essential layer underlying consciousness is supported by research correlating DMN connectivity to level of consciousness in brain-damaged patients [53], behavioral signs of awareness [155], and some meditative experiences [156]. We assert that intrinsic brain activity uses so much energy due to its function in maintaining the neural framework that founds the subconscious $3 \mathrm{D}$ virtual matrix necessary for conscious perceptions [12]. In addition, intrinsic activity from the DMN likely models our experience of being a unified self, centered in space in direct relation to the subconscious $3 \mathrm{D}$ virtual space [85]. This intrinsic activity modulates, influences, and supports high-level oscillatory processes involved in cognition [157], memory [158], learning [159], and other functions of mind, unifying them all by binding them to the virtual space framework.

Baars explained how "a serial, integrated and very limited stream of consciousness emerges from a nervous system that is mostly unconscious, distributed, parallel and of enormous capacity" [160]. Thus, unconscious activity is at the bottom of multiple dimensions of hierarchy. Understanding the difference between the hierarchy of unconscious to conscious physiological activity would greatly advance the knowledge of what consciousness really is, and so this understanding is a prime focus in cognition research [161] [162] [163]. Eagleman has thoroughly explored the vast domination of the unconscious mind in our behaviors and thoughts, describing the conscious mind as "a stowaway on a transatlantic steam ship, taking credit for the journey without acknowledging the massive engineering underfoot" [45]. The Fingelkurts have described the lowest layer of the brain-mind hierarchy (micro-to-macro) which supports the upper layers as the physical, molecular operations of neurons which may better be 


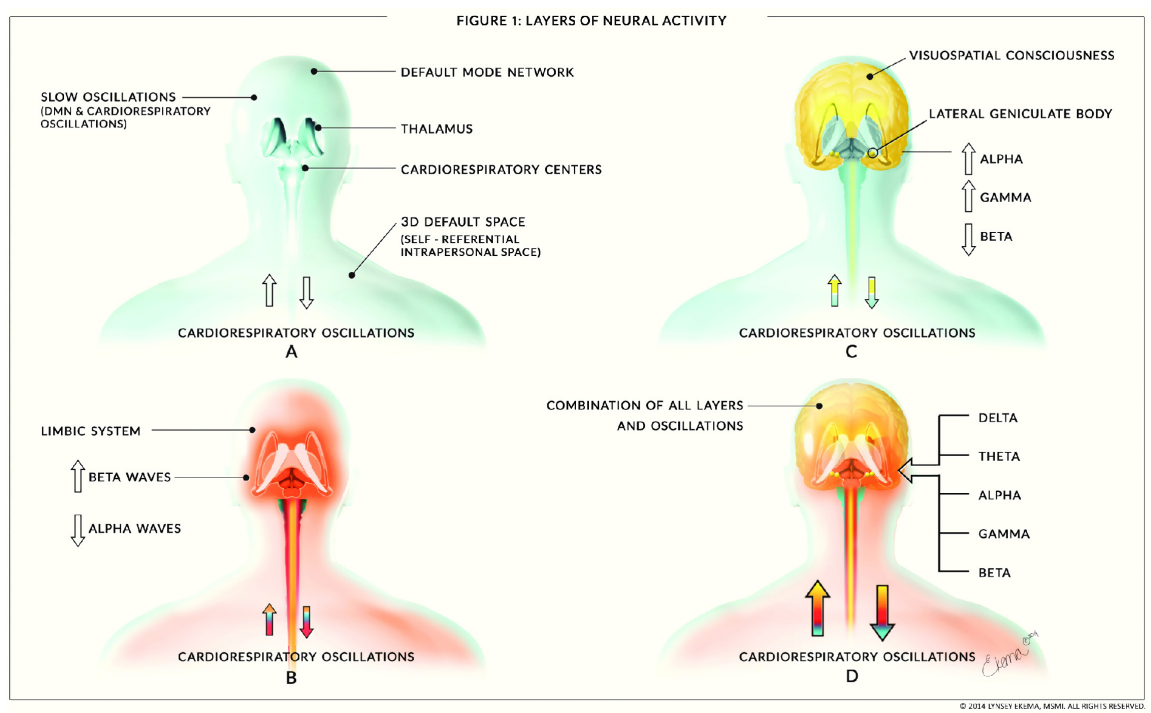

Figure 3. Layers of Neural Activity. This figure represents the hierarchical organization of oscillatory activity proposed by the DST which forms the bioelectric structure of consciousness. The thalamus is the main hub of this structure and coordinates activity of all layers. The colors illustrate how the layers are stacked upon each other, with the basic layer in blue entraining the layers above it which are redder. Bi-directional arrows are shown for each layer as cardiorespiratory influence with neural activity is reentrant with all layers. In the first layer (A), ultra-low frequency oscillations of the default mode network, other salient networks, and cardiorespiratory activities form a foundation for other layers to build upon. The cardiorespiratory activity groups, entrains, and organizes the most fundamental bioelectric activity which creates the $3 \mathrm{D}$, subconscious, virtual space where consciousness is housed. The neural activity of this layer uses the majority of the energy utilized by the brain to maintain. Slightly higher frequency activity of the DMN creates a sense of self inside this 3D virtual space. The second layer, (B), consists of primitive bioelectric activity such as limbic activity which plays a vital survival role through controlling basic emotions and drives such as fear, pleasure, hunger, and anger. The top layer of the oscillatory hierarchy, (C), consist of corticothalamic activity most associated with consciousness and which is involved in many cognitive and conscious processes. This layer is responsible for higher-level cognition such as problem solving as well as the integration and unification of sensory qualia into the lower level 3D virtual space along with tying sensation to emotional drives. The lateral geniculate body is the part of the thalamus which helps create visual consciousness by integrating visual input and cortical activity. (D) Represents the sum of all layers consisting of all physiological oscillations (Image previously published in [12]. Permission provided by Creative Commons license).

described as nonconscious [32], as this layer lacks any experiential ontology [164]. They describe how at the next brain-mind layer the conscious/unconscious border exists. This is the layer of transient functional neural assemblies which support basic cognitive operations [32]. On top of this hierarchy exists the layer producing reflective consciousness, which is the synchronization of complex macro operations into the greatest level of complexity and abstraction [1] [165].

\section{From Embodied Cognition to Embodied Consciousness}

Embodied cognition is the "radical" field of hypotheses that the brain is not the sole cognitive resource and that our bodies play a significant role in our psy- 
chologies [166]. Although this approach is a traditional, holistic aspect of eastern medicine, it is relatively new to cognitive science and is considered radical because it rejects the "mind as a computer" metaphor [167]. In embodied cognitive science, many models of psychological and biological systems consider the brain, mind, and body as a single entity in a holistic manner. Although embodied cognition is not unified in its established definitions and research goals [168], a general view is that the body not only affects the mind, but the mind affects the body via dynamic interactions [169]. Although speculative we extend this idea to consciousness, propounding the body plays a significant role in the emergence of consciousness. Although there is not sufficient evidence to fully consider this concept a principle as of yet, we feel strongly enough about the importance of the body and promoting research into it that we have included it.

A growing body of research shows that the cognitive system is highly dependent on sensory and motor functions of the body, suggesting that sensing and acting should be considered an essential aspect of higher-level cognition [170]. For example, holding a warm cup of coffee versus a cold one leads participants to judge a new acquaintance as more trustworthy after a brief interaction [171]. Thinking about the future caused participants to lean slightly forward, while thinking about the past caused them to lean slightly backward [172]. Force laughter and smiling substantially improves mood in participants [173]. Although these studies are based on primary experiences, further research into the physiology of brain-body unity will likely ground the embodiment hypothesis in more physical, biological science. The DST has extended this embodiment science to include a greater physiological and psychological perspective on consciousness, further including the sensory organs and respiratory and cardiovascular systems as crucial components and influencers of mind which have received little attention in the embodiment sciences literature.

Lateral Inhibition has been well researched and known to be a crucial mechanism in many types of sensory perception [174] [76] [176] [177]. We have proposed how a synchrony among the cortex and sensory organs allows the body and brain to conglomerate together as a single UMC which thus allows an extension of top-down effects and information to the sensory organs [109]. According to this embodied perspective, sensory organs not only initiate transduction of incoming external stimuli, but are an active component of physiologic processes isomorphic to the perceptual experiences that occur [18]. We propose this occurs via a process best described "lateral inhibition across abstract dimensions" [178]. Although lateral inhibition is commonly referenced in a local, spatial sense, we refer to it in a functional sense. This refers to interactions that occur at a distance between the cortex and sensory organs but remain functionally connected through oscillatory synchronization. Through this type of lateral inhibition or even amplification, sensory stimuli can become amplified or filtered based on the current state of the internal world simulation which allows for expectations about incoming stimuli to be formed [18]. Top-down amplification 
has been studied showing that there can be amplification at 100,000 times greater than the result of stimuli alone [179].

According to the DST, membrane potential oscillations (MPOs) between the thalamus and sensory organs along their afferent fibers are integrated with cortical activity by the thalamus, providing a medium for top-down feedback [18]. This hypothesis is supported in part by the fact that prodigious top-down projections to the thalamus and brainstem from (somato)sensory cortices actually outnumber bottom-up projections (at least 3:1) [131] [180] [181] and that these descending projections in some cases extend to the sensory organs such as the retina [181]. MPOs have also been observed on afferent fibers, modulating sensory signals to the brain [182]. Projections from the retina to the lateral geniculate nucleus, which is the thalamic relay center from the retina to the occipital lobe [183], have been shown to oscillate with such nucleus via which synchrony is further created with the visual and association cortices [184] [185].

The top-down feedback to the thalamus and brainstem is fundamental in implementing sensory predictions [60] [181] but traditionally has been neglected [131]. Thus, we have thus extended these well-known projections to the thalamus to the sensory organs themselves via bioelectric synchrony (Figure 4). Sensory organs may thus be more influenced by the thalamocortical system than by actual external stimuli. For example, if one is walking in the woods and comes across a stick that looks like a snake, one may briefly see an actual snake due to the emotionally strong top-down indication of seeing one. In this brief moment, before the realization occurs, the "image" of a snake may exist on the retina itself even though the true external stimulus is that of a stick. This is because the top-down effects are strong enough to cause the retinal cells to signal each "pixel" of an internally generated, 3D image.

As mentioned in the thalamus principle, Edelman asserts that conscious sensory perception emerges from coherent synchrony among multiple distal cortical areas maintained by reentrant activity among the thalamocortical network [59]. The Fingelkurts describe sensory consciousness as originating from "operational modules" of bioelectric synchronies between functional brain modules that integrate together forming a global metastable continuum responsible for the integrated and unified experience [1] [32] [93]. The DST, however, extends these concepts to the peripheral nervous system by describing how the thalamus not only forms such feedback loops with the cortex but also with sensory organs of the body via MPOs and integrates these loops together [109]. We have deemed these reentrant loops with the body "thalamosomatic loops".

MPOs are ideally suited to provide efferent feedback to sensory receptors as they can co-occur on afferent fibers and provide a medium for bioelectric synchronization [186]. MPOs have been shown to play key roles in perceptual and other signal processing [187] [188] as well as encoding information [189]. Neurons may adjust their firing patterns based on MPOs [188], enabling very precise control of neuronal firing [186]. MPOs are also suggested to work as a priming 


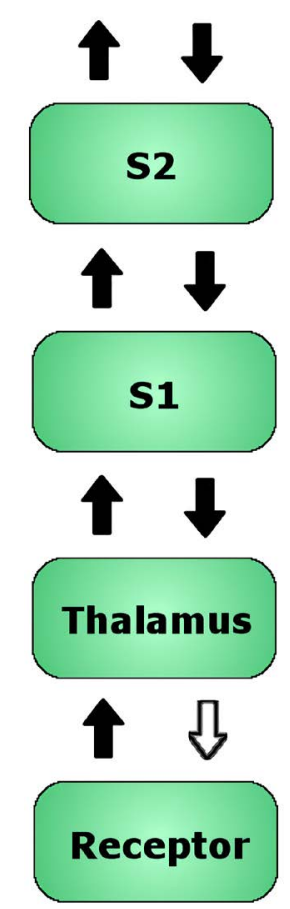

Figure 4. Top-down processing may include sensory receptors. This simple flowchart illustrates known top-down feedback and bottom-up feedforward flow in the somatosensory system as an example. On the afferent route, a tactile stimulus is transferred to the thalamus, to the primary and then secondary somatosensory cortex. Information is then sent to a variety of association and other cortices. Top-down influences which modulate the processing of incoming stimuli via expectations derived from experience and knowledge travel downstream or along the efferent route. Thus, stimuli meaningful to the current task can be selected for, allowing for fast and reliable sensory processing. The unfilled arrow represents known descending projections to sensory organs and our addition to this sensory model, top-down bioelectric influences extending to the sensory receptors via membrane potential oscillations. Adapted from [60], Permission by CCC.

mechanism, priming synapses and networks to receive certain input based on expectations [60]. According to this top-down MPO model, in the case of vision, the many modules of the visual cortex that process color, distance, space, and motion would be appropriately synchronized with the photoreceptors of the retina [18]. They would not directly synchronized, but the thalamus would act as the intermediary or hub between the central and peripheral nervous systems, integrating diverse activity from the cortex and projecting the top-down signals to the respective sensory organs. Through this oscillatory synchronization, the sensory receptors can expect certain stimuli to fall upon them, and can begin to process incoming stimuli at the site of the receptors facilitating near immediate conscious awareness of external sensation [18].

We and others have recognized respiration as an influencer and even fundamental component of the dynamic bioelectric activity occurring throughout the brain [151] [190] [191] [192] [193] (and potentially body) [8]. In the hierarchical model of the DST described, the lowest layer involves intrinsic neural and cardiorespiratory activity that while unconscious, are vital to the higher order func- 
tional activity that gives rise to consciousness [12]. The low frequency oscillations of breathing have been thought to drive a broad range of oscillations throughout the brain [151] as well as modulate cortical functions, including emotional and cognitive processes [194]. Local field potential oscillations reveal respiration-entrained rhythms that do not have standard oscillatory properties [195]. These rhythms have been shown to be more widespread than previously believed and ourselves and other authors assert that they represent a global coherence mechanism [151].

Respiration-entrained rhythms are suggested to exist in order to sustain and maintain unification and coherence among neuronal oscillatory activity, exerting significant influence on movement, sensation, and cognitive processes [191]. Thus, the main mechanism by which the body influences the brain is via the modulation of neural oscillatory synchronization by sensory inputs throughout the body [191]. The DST takes this further by asserting oscillatory synchronization throughout the body as well as the brain [11], and suggests that respiration may even dynamically modulate neuronal membrane potentials [196]. Motor activity has been tied to respiration through demonstration that handgrip force is significantly stronger during forced expiration than during forced inspiration [197], and eye movements have been shown to be phase-locked to respiration [198]. The influence on sensation by respiration has been substantiated through research on visual and auditory signal detection, revealing that the threshold for signal detection is higher during inspiration compared to expiration [199]. In addition, during controlled breathing, reaction times are significantly increased during expiration compared to inspiration [192] [200].

Due to this significant influence of breathing on neural activity, we have proposed how we may regulate this activity globally by regulating our breathing patterns [201]. This is the foundation of our assertion that meditative breathing exercises may be more overall effective in treating emotional disorders such as anxiety and depression than pharmaceutical approaches [201]. There is a strong correlative relationship between respiration rates and autonomic activity, with higher respiration rates stimulating the sympathetic [202] and lower rates stimulating the parasympathetic tone [203]. Research into how controlled slow breathing optimizes homeostatic parameters and promotes health and longevity [203] may reveal integral, vital activities of the unified biological system that is our brain and body.

The heart may also influence the mind via cardiorespiratory synchronization which is a coupling between the heart beat and the respiratory phase often occurring during sleep or anesthesia, and while it has been under investigation for twenty years, no clear clinical implications have been substantiated [204]. High levels of cardiorespiratory synchronization occurring during meditative breathing practices may play a role in the resulting modulation of the autonomic system, amygdala activity, and the relaxation response [205]. Stress is associated with a sympathetic response and a decrease in cardiorespiratory synchronization 


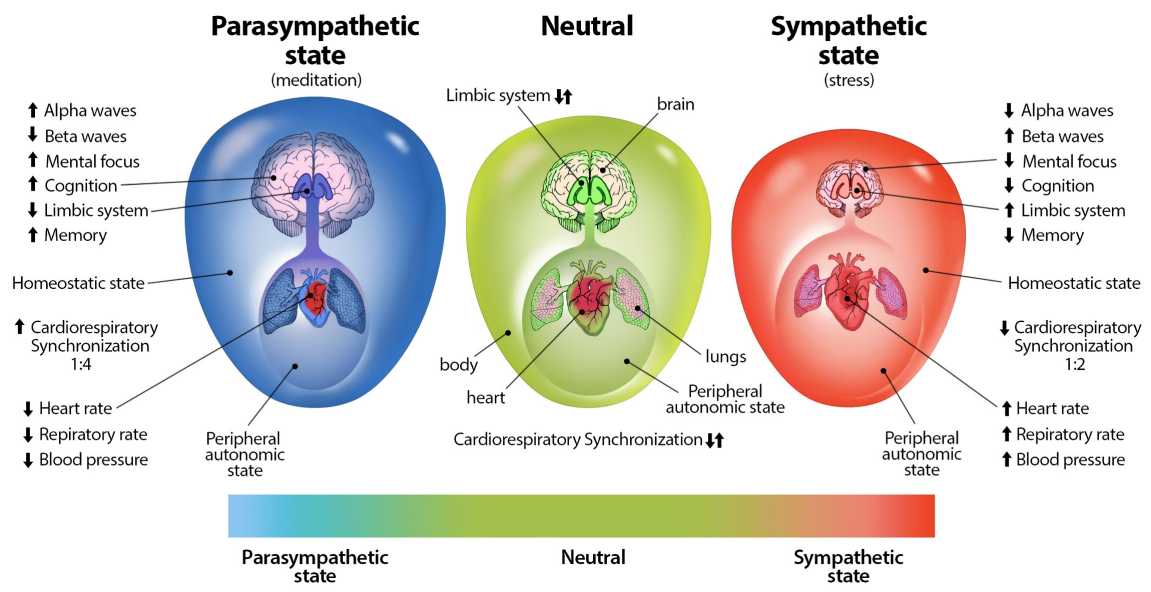

Figure 5. An Embodied Cognition Spectrum of Autonomic and Homeostatic States. This figure illustrates a spectrum of cognitive states which correspond to physiological states of the body. The negative end of the spectrum identified with a distressed state of mind is linked to a sympathetic dominant state of the autonomic nervous system and the positive end, a relaxed state of mind, corresponds to parasympathetic dominance. The body-brain connection is stronger in the relaxed state indicating increased coherence between neural and bodily processes. The size of the brain represents overall cognitive capacity and its ability to modulate homeostasis in a long-term, healthy manner. The state of parasympathetic dominance can be cultured through meditative techniques and allow for better cognitive flexibility and emotional control. Overall, this system illustrates how the brain and body are unified in producing the conscious experience (Figure by Michael Jensen MSMI, CMI. Image previously published in [8]. Permission provided by Creative Commons license)

[206]. The hyper-sympathetic state is also correlated with a plethora of chronic diseases such as heart disease and even obesity [207]. Modern lifestyles and goals have been proposed to be behind a widespread and persisting sympathetic over-activation due to an evolutionary mismatch between our predictable, pre-history, tribal lifestyles and the modern hectic lifestyles we live today [208] [209]. By regulating our breathing, we may be able to reduce the ill effects of disrupted sympathovagal balance, enhance poor autonomic reactivity to stress [203], and control otherwise unconscious bodily processes [202] (Figure 5).

\section{Conclusion}

Consciousness is proposed to be an emergent property from the complex biological systems that we are. The perspective on which concepts can be considered principles of consciousness has been derived from agreements among top models and their top insights, along with our own hypotheses. This perspective is largely through the lens of the Default Space Theory which is novel and yet can be understood as an expansion of other powerful metastable models such as the Global Workspace Theory and the Operational Architectonics Theory. It is distinct from other metastable models of consciousness in its embodied architecture which extends the unified metastable continuum to the body, not solely the brain. The foundations of human consciousness we have explored may likely 
be answers to the "easy" or "real" problems of conscious. Only when we solve the "real problem" of consciousness, how we can account for consciousness in terms of biological mechanisms, can we begin to ponder the "hard problem", the physical nature of how conscious experiences arise solely from the physics of chemistry, electromagnetism, and kinetics that are the basic mechanisms of the body and brain. Through understanding principles of consciousness, modern medicine may make greater strides in developing therapies for cognitive medical conditions and cognitive/computer scientists may even ignite a new age of artificial intelligence.

\section{Acknowledgements}

Funding has been provided by Charitable Medical Healthcare Foundation.

\section{Authors' Contribution}

Theory developed by RJ with some writing with the majority of the manuscript written by CB.

\section{Funding}

Funding provided by Charitable Medical Healthcare Foundation.

\section{Conflicts of Interest}

The authors declare no conflict of interest.

\section{References}

[1] Fingelkurts, A.A., Fingelkurts, A.A. and Neves, C.F.H. (2013) Consciousness as a Phenomenon in the Operational Architectonics of Brain Organization: Criticality and Self-Organization Considerations. Chaos, Solitons \& Fractals, 55, 13-31. https://doi.org/10.1016/j.chaos.2013.02.007

[2] Revonsuo, A. (2006) Inner Presence: Consciousness as a Biological Phenomenon. MIT Press, Cambridge.

[3] Morcom, A.M. and Fletcher, P.C. (2007) Does the Brain Have a Baseline? Why We Should Be Resisting a Rest. NeuroImage, 37, 1073-1082. https://doi.org/10.1016/j.neuroimage.2006.09.013

[4] Berger, H. (1929) Über das elektrenkephalogramm des menschen. European Archives of Psychiatry and Clinical Neuroscience, 87, 527-570. https://doi.org/10.1007/BF01797193

[5] Buckner, R.L., Andrews-Hanna, J.R. and Schacter, D.L. (2008) The Brain's Default Network. Annals of the New York Academy of Sciences, 1124, 1-38. https://doi.org/10.1196/annals.1440.011

[6] Tononi, G. (2004) An Information Integration Theory of Consciousness. BMC Neuroscience, 5, 42. https://doi.org/10.1186/1471-2202-5-42

[7] Oizumi, M., Albantakis, L. and Tononi, G. (2014) From the Phenomenology to the Mechanisms of Consciousness: Integrated Information Theory 3.0. PLOS Computational Biology, 10, e1003588. https://doi.org/10.1371/journal.pcbi.1003588

[8] Jerath, R., Crawford, M.W. and Barnes, V.A. (2015) A Unified 3D Default Space 
Consciousness Model Combining Neurological and Physiological Processes That Underlie Conscious Experience. Frontiers in Psychology, 6, 1204. https://doi.org/10.3389/fpsyg.2015.01204

[9] Zeman, A. (2005) What in the World Is Consciousness? In: Laureys, S., Ed., Progress in Brain Research, Elsevier, Amsterdam, 1-10. https://doi.org/10.1016/S0079-6123(05)50001-3

[10] Jerath, R., Beveridge, C. and Jensen, M. (2018) Conceptual Advances in the Default Space Model of Consciousness. World Journal of Neuroscience, 8, 254-269. https://doi.org/10.4236/wjns.2018.82020

[11] Jerath, R. and Beveridge, C. (2018) Top Mysteries of the Mind: Insights from the Default Space Model of Consciousness. Frontiers in Human Neuroscience, 12, 162. https://doi.org/10.3389/fnhum.2018.00162

[12] Jerath, R. and Crawford, M.W. (2015) Layers of Human Brain Activity: A Functional Model Based on the Default Mode Network and Slow Oscillations. Frontiers in Human Neuroscience, 9, 248. https://doi.org/10.3389/fnhum.2015.00248

[13] Jerath, R. and Beveridge, C. (2019) Multimodal Integration and Phenomenal Spatiotemporal Binding: A Perspective from the Default Space Theory. Frontiers in Integrative Neuroscience, 13, 2. https://doi.org/10.3389/fnint.2019.00002

[14] Jung, C.G. (2014) Analytical Psychology: Its Theory and Practice. Routledge, New York. https://doi.org/10.4324/9781315772202

[15] Tononi, G. and Koch, C. (2015) Consciousness: Here, There and Everywhere? Philosophical Transactions of the Royal Society of London. Series B, Biological Sciences, 370, Article ID: 20140167. https://doi.org/10.1098/rstb.2014.0167

[16] Celeghin, A., et al. (2017) Basic Emotions in Human Neuroscience: Neuroimaging and Beyond. Frontiers in Psychology, 8, 1432.

https://doi.org/10.3389/fpsyg.2017.01432

[17] Purves, D., et al. (2018) Neuroscience. 6th Edition, Sinauer Associates, New York.

[18] Jerath, R., et al. (2016) How Lateral Inhibition and Fast Retinogeniculo-Cortical Oscillations Create Vision: A New Hypothesis. Medical Hypotheses, 96, 20-29. https://doi.org/10.1016/j.mehy.2016.09.015

[19] Thompson, E. and Varela, F.J. (2001) Radical Embodiment: Neural Dynamics and Consciousness. Trends in Cognitive Sciences, 5, 418-425. https://doi.org/10.1016/S1364-6613(00)01750-2

[20] Varela, F., et al. (2001) The Brainweb: Phase Synchronization and Large-Scale Integration. Nature Reviews Neuroscience, 2, 229. https://doi.org/10.1038/35067550

[21] Revonsuo, A. and Newman, J. (1999) Binding and Consciousness. Consciousness and Cognition, 8, 123-127. https://doi.org/10.1006/ccog.1999.0393

[22] Fingelkurts, A.A., Fingelkurts, A.A. and Neves, C.F.H. (2009) Phenomenological Architecture of a Mind and Operational Architectonics of the Brain: The Unified Metastable Continuum. New Mathematics and Natural Computation, 5, 221-244. https://doi.org/10.1142/S1793005709001258

[23] Hesslow, G. (2002) Conscious Thought as Simulation of Behaviour and Perception. Trends in Cognitive Sciences, 6, 242-247. https://doi.org/10.1016/S1364-6613(02)01913-7

[24] Grush, R. (2004) The Emulation Theory of Representation: Motor Control, Imagery, and Perception. Behavioral and Brain Sciences, 27, 377-442. https://doi.org/10.1017/S0140525X04000093

[25] Metzinger, T. (2003) Being No-One. MIT Press, Cambridge. 
https://doi.org/10.7551/mitpress/1551.001.0001

[26] Trehub, A. (2007) Space, Self, and the Theater of Consciousness. Consciousness and Cognition, 16, 310-330. https://doi.org/10.1016/j.concog.2006.06.004

[27] Craik, K. (1943) The Nature of Explanation. Cambridge University Press, Cambridge.

[28] Hume, D. (1739) A Treatise of Human Nature. Oxford University Press, Oxford. https://doi.org/10.1093/oseo/instance.00046221

[29] Kössl, M. and Hechavarría, J. (2018) Smart Bats Click Twice. eLife, 7, e36561. https://doi.org/10.7554/eLife.36561

[30] Kothari, N.B., Wohlgemuth, M.J. and Moss, C.F. (2018) Dynamic Representation of 3D Auditory Space in the Midbrain of the Free-Flying Echolocating Bat. eLife, 7, e29053. https://doi.org/10.7554/eLife.29053

[31] Cadena, C., et al. (2016) Past, Present, and Future of Simultaneous Localization and Mapping: Toward the Robust-Perception Age. IEEE Transactions on Robotics, 32, 1309-1332. https://doi.org/10.1109/TRO.2016.2624754

[32] Fingelkurts, A.A., Fingelkurts, A.A. and Neves, C.F.H. (2010) Natural World Physical, Brain Operational, and Mind Phenomenal Space-Time. Physics of Life Reviews, 7, 195-249. https://doi.org/10.1016/j.plrev.2010.04.001

[33] Hyafil, A., et al. (2015) Neural Cross-Frequency Coupling: Connecting Architectures, Mechanisms, and Functions. Trends in Neurosciences, 38, 725-740. https://doi.org/10.1016/j.tins.2015.09.001

[34] Sirota, A. and Buzsaki, G. (2005) Interaction between Neocortical and Hippocampal Networks via Slow Oscillations. Thalamus \& Related Systems, 3, 245-259. https://doi.org/10.1017/S1472928807000258

[35] Rusalova, M.N. (2006) Frequency-Amplitude Characteristics of the EEG at Different Levels of Consciousness. Neuroscience and Behavioral Physiology, 36, 351-358. https://doi.org/10.1007/s11055-006-0024-x

[36] Babiloni, C., et al. (2009) Cortical Sources of Resting-State Alpha Rhythms Are Abnormal in Persistent Vegetative State Patients. Clinical Neurophysiology, 120, 719-729. https://doi.org/10.1016/j.clinph.2009.02.157

[37] Fingelkurts, A.A., et al. (2012) Toward Operational Architectonics of Consciousness: Basic Evidence from Patients with Severe Cerebral Injuries. Cognitive Processing, 13, 111-131. https://doi.org/10.1007/s10339-011-0416-X

[38] Fingelkurts, A.A., et al. (2012) EEG Oscillatory States as Neuro-Phenomenology of Consciousness as Revealed from Patients in Vegetative and Minimally Conscious States. Consciousness and Cognition, 21, 149-169. https://doi.org/10.1016/j.concog.2011.10.004

[39] Fingelkurts, A.A., et al. (2012) DMN Operational Synchrony Relates to Self-Consciousness: Evidence from Patients in Vegetative and Minimally Conscious States. The Open Neuroimaging Journal, 6, 55-68. https://doi.org/10.2174/1874440001206010055

[40] Jerath, R. and Crawford, M.W. (2014) Neural Correlates of Visuospatial Consciousness in 3D Default Space: Insights from Contralateral Neglect Syndrome. Consciousness and Cognition, 28, 81-93. https://doi.org/10.1016/j.concog.2014.06.008

[41] Driver, J. and Vuilleumier, P. (2001) Perceptual Awareness and Its Loss in Unilateral Neglect and Extinction. Cognition, 79, 39-88. https://doi.org/10.1016/S0010-0277(00)00124-4 
[42] Smythies, J.R. (2003) Space, Time and Consciousness. Journal of Consciousness Studies, 10, 47-56.

[43] Maldonato, M. and Dell'Orco, S. (2012) The Predictive Brain. World Futures, 68, 381-389. https://doi.org/10.1080/02604027.2012.693846

[44] Herrera Giraldo, C.E. (2018) The Cavern of the Eye: Seeing through the Retina. In: Microbes and Other Shamanic Beings, Palgrave Macmillan, Cham, 119-128.

[45] Eagleman, D. (2011) Incognito: The Secret Lives of the Brain. Pantheon, New York.

[46] Metzinger, T. (2013) Why Are Dreams Interesting for Philosophers? The Example of Minimal Phenomenal Selfhood, plus an Agenda for Future Research. Frontiers in Psychology, 4, 746. https://doi.org/10.3389/fpsyg.2013.00746

[47] Snyder, T.J. and Gackenbach, J. (1988) Individual Differences Associated with Lucid Dreaming. In: Gackenbach, J. and La Berge, S., Eds., Conscious Mind, Sleeping Brain, Plenum, New York, 221-259. https://doi.org/10.1007/978-1-4757-0423-5_10

[48] Strauch, I. and Meier, B. (1996) In Search of Dreams. Results of Experimental Dream Research. SUNY Press, New York.

[49] Valli, K., et al. (2005) The Threat Simulation Theory of the Evolutionary Function of Dreaming: Evidence from Dreams of Traumatized Children. Consciousness and Cognition, 14, 188-218. https://doi.org/10.1016/S1053-8100(03)00019-9

[50] Revonsuo, A. and Valli, K. (2000) Dreaming and Consciousness: Testing the Threat Simulation Theory of the Function of Dreaming. Psyche: An Interdisciplinary Journal of Research on Consciousness, 6.

[51] Gordon, R.M. (1986) Folk Psychology as Simulation. Mind \& Language, 1, 158-171. https://doi.org/10.1111/j.1468-0017.1986.tb00324.x

[52] Jeannerod, M. and Frak, V. (1999) Mental Imaging of Motor Activity in Humans. Current Opinion in Neurobiology, 9, 735-739.

https://doi.org/10.1016/S0959-4388(99)00038-0

[53] Vanhaudenhuyse, A., et al. (2010) Default Network Connectivity Reflects the Level of Consciousness in Non-Communicative Brain-Damaged Patients. Brain: A Journal of Neurology, 133, 161-171. https://doi.org/10.1093/brain/awp313

[54] Fox, M.D., et al. (2005) The Human Brain Is Intrinsically Organized into Dynamic, Anti-Correlated Functional Networks. Proceedings of the National Academy of Sciences of the United States of America, 102, 9673-9678.

https://doi.org/10.1073/pnas.0504136102

[55] Raichle, M.E. and Snyder, A.Z. (2007) A Default Mode of Brain Function: A Brief History of an Evolving Idea. Neuroimage, 37, 1083-1090. https://doi.org/10.1016/j.neuroimage.2007.02.041

[56] Plum, F. (1991) Coma and Related Global Disturbances of the Human Conscious State. In: Peters, A. and Jones, E.G., Eds., Normal and Altered States of Function, Plenum Press, New York, 359-425. https://doi.org/10.1007/978-1-4615-6622-9_9

[57] LeDoux, J. (2012) Rethinking the Emotional Brain. Neuron, 73, 653-676. https://doi.org/10.1016/j.neuron.2012.02.004

[58] Min, B.K. (2010) A Thalamic Reticular Networking Model of Consciousness. Theoretical Biology and Medical Modelling, 7, 10. https://doi.org/10.1186/1742-4682-7-10

[59] Edelman, G.M., Gally, J.A. and Baars, B.J. (2011) Biology of Consciousness. Frontiers in Psychology, 2, 4. https://doi.org/10.3389/fpsyg.2011.00004

[60] Engel, A.K., Fries, P. and Singer, W. (2001) Dynamic Predictions: Oscillations and Synchrony in Top-Down Processing. Nature Reviews Neuroscience, 2, 704-716. 
https://doi.org/10.1038/35094565

[61] Singer, W. (2001) Consciousness and the Binding Problem. Annals of the New York Academy of Sciences, 929, 123-146. https://doi.org/10.1111/j.1749-6632.2001.tb05712.x

[62] Passingham, R.E., Stephan, K.E. and Kötter, R. (2002) The Anatomical Basis of Functional Localization in the Cortex. Nature Reviews Neuroscience, 3, 606. https://doi.org/10.1038/nrn893

[63] Tononi, G. and Edelman, G.M. (2000) A Universe of Consciousness: How Matter Becomes Imagination. Basic Books, New York.

[64] Demiralp, T., et al. (2006) The Interaction of Theta and Gamma Oscillations in Human Cognition. International Journal of Psychophysiology, 61, 309.

[65] Baars, B.J., Franklin, S. and Ramsoy, T.Z. (2013) Global Workspace Dynamics: Cortical "Binding and Propagation" Enables Conscious Contents. Frontiers in Psychology, 4, 200. https://doi.org/10.3389/fpsyg.2013.00200

[66] Jones, E.G. (2007) The Thalamus. 2nd Edition, Cambridge University Press, Cambridge.

[67] Steriade, M. (2006) Grouping of Brain Rhythms in Corticothalamic Systems. Neuroscience, 137, 1087-1106. https://doi.org/10.1016/j.neuroscience.2005.10.029

[68] Modha, D.S. and Singh, R. (2010) Network Architecture of the Long-Distance Pathways in the Macaque Brain. Proceedings of the National Academy of Sciences of the United States of America, 107, 13485-13490. https://doi.org/10.1073/pnas.1008054107

[69] Llinas, R., et al. (1998) The Neuronal Basis for Consciousness. Philosophical Transactions of the Royal Society B: Biological Sciences, 353, 1841-1849. https://doi.org/10.1098/rstb.1998.0336

[70] Dehaene, S., Sergent, C. and Changeux, J.-P. (2003) A Neuronal Network Model Linking Subjective Reports and Objective Physiological Data during Conscious Perception. Proceedings of the National Academy of Sciences, 100, 8520-8525. https://doi.org/10.1073/pnas.1332574100

[71] Dehaene, S. and Changeux, J.-P. (2011) Experimental and Theoretical Approaches to Conscious Processing. Neuron, 70, 200-227. https://doi.org/10.1016/j.neuron.2011.03.018

[72] Purves, D., et al. (2018) Emotion. In: Neuroscience, Sinauer Associates, New York, 704-723.

[73] Bogen, J.E. (1997) Some Neurophysiologic Aspects of Consciousness. Seminars in Neurology, 17, 95-103. https://doi.org/10.1055/s-2008-1040918

[74] Stookey, B., Scarff, J. and Teitelbaum, M. (1941) Frontal Lobectomy in the Treatment of Brain Tumors. Annals of Surgery, 113, 161-169. https://doi.org/10.1097/00000658-194102000-00001

[75] Milner, B., Corkin, S. and Teuber, H.L. (1968) Further Analysis of the Hippocampal Amnesic Syndrome: 14-Year Follow-Up Study of H.M. Neuropsychologia, 6, 215-234. https://doi.org/10.1016/0028-3932(68)90021-3

[76] Verschuuren, J., et al. (1996) Inflammatory Infiltrates and Complete Absence of Purkinje Cells in Anti-Yo-Associated Paraneoplastic Cerebellar Degeneration. Acta Neuropathologica, 91, 519. https://doi.org/10.1007/s004010050460

[77] Austin, G.M. and Grant, F.C. (1956) Physiologic Observations Following Total Hemispherectomy in Man. Surgery, 38, 239-258.

[78] Bruce, B.B., et al. (2004) Aphasia and Thalamotomy: Important Issues. Stereotactic 
and Functional Neurosurgery, 82, 186-190. https://doi.org/10.1159/000082207

[79] Shah, S.A. and Schiff, N.D. (2010) Central Thalamic Deep Brain Stimulation for Cognitive Neuromodulation-A Review of Proposed Mechanisms and Investigational Studies. European Journal of Neuroscience, 32, 1135-1144. https://doi.org/10.1111/j.1460-9568.2010.07420.x

[80] Kay, L.M. and Sherman, S.M. (2007) An Argument for an Olfactory Thalamus. Trends in Neurosciences, 30, 47-53. https://doi.org/10.1016/j.tins.2006.11.007

[81] Ward, L.M. (2013) The Thalamus: Gateway to the Mind. Wiley Interdisciplinary Reviews. Cognitive Science, 4, 609-622. https://doi.org/10.1002/wcs.1256

[82] Tyll, S., Budinger, E. and Noesselt, T. (2011) Thalamic Influences on Multisensory Integration. Communicative \& Integrative Biology, 4, 378-381. https://doi.org/10.4161/cib.15222

[83] Alkire, M.T., Haier, R.J. and Fallon, J.H. (2000) Toward a Unified Theory of Narcosis: Brain Imaging Evidence for a Thalamocortical Switch as the Neurophysiologic Basis of Anesthetic-Induced Unconsciousness. Consciousness and Cognition, 9, 370-386. https://doi.org/10.1006/ccog.1999.0423

[84] Steriade, M., McCormick, D. and Sejnowski, T. (1993) Thalamocortical Oscillations in the Sleeping and Aroused Brain. Science, 262, 679-685. https://doi.org/10.1126/science.8235588

[85] Fingelkurts, A.A., Fingelkurts, A.A. and Kallio-Tamminen (2016) Long-Term Meditation Training Induced Changes in the Operational Synchrony of Default Mode Network Modules during a Resting State. Cognitive Processing, 17, 27. https://doi.org/10.1007/s10339-015-0743-4

[86] Chen, A.C., et al. (2013) Causal Interactions between Fronto-Parietal Central Executive and Default-Mode Networks in Humans. Proceedings of the National Academy of Sciences of the United States of America, 110, 19944-19949. https://doi.org/10.1073/pnas.1311772110

[87] Chklovskii, D.B. and Koulakov, A.A. (2004) Maps in the Brain: What Can We Learn from Them? Annual Review of Neuroscience, 27, 369-392. https://doi.org/10.1146/annurev.neuro.27.070203.144226

[88] Patel, G.H., Michael, D.K. and Snyder, L.H. (2014) Topographic Organization in the Brain: Searching for General Principles. Trends in Cognitive Sciences, 18, 351-363. https://doi.org/10.1016/j.tics.2014.03.008

[89] Jerath, R., et al. (2016) Functional and Neural Mechanisms of Out-of-Body Experiences: Importance of Retinogeniculo-Cortical Oscillations. World Journal of Neuroscience, 6, 287-302. https://doi.org/10.4236/wjns.2016.64032

[90] Won, A.S., Bailenson, J.N. and Lanier, J. (2015) Homuncular Flexibility: The Human Ability to Inhabit Nonhuman Avatars. In: Emerging Trends in the Social and Behavioral Sciences, John Wiley \& Sons, Hoboken. https://doi.org/10.1002/9781118900772.etrds0165

[91] Gonzalez-Franco, M. and Lanier, J. (2017) Model of Illusions and Virtual Reality. Frontiers in Psychology, 8, 1125. https://doi.org/10.3389/fpsyg.2017.01125

[92] Kelso, J.A.S. and Tognoli, K. (2007) Toward a Complementary Neuroscience: Metastable Coordination Dynamics of the Brain. In: Perlovsky, L. and Kozma, R., Eds., Neurodynamics of Cognition and Consciousness, Understanding Complex Systems, Springer, Berlin, Heidelberg, 39-59. https://doi.org/10.1007/978-3-540-73267-9_3

[93] Fingelkurts, A.A. and Fingelkurts, A.A. (2001) Operational Architectonics of the Human Brain Biopotential Field: Towards Solving the Mind-Brain Problem. Brain 
and Mind, 2, 261-296. https://doi.org/10.1023/A:1014427822738

[94] Fingelkurts, A.A. and Fingelkurts, A.A. (2004) Making Complexity Simpler: Multivariability and Metastability in the Brain. International Journal of Neuroscience, 114, 843-862. https://doi.org/10.1080/00207450490450046

[95] Fingelkurts, A.A. and Fingelkurts, A.A. (2017) Information Flow in the Brain: Ordered Sequences of Metastable States. Information, 8, 22. https://doi.org/10.3390/info8010022

[96] Freeman, W.J. and Holmes, M.D. (2005) Metastability, Instability, and State Transition in Neocortex. Neural Networks, 18, 497-504.

https://doi.org/10.1016/j.neunet.2005.06.014

[97] Fingelkurts, A.A., et al. (2006) Composition of Brain Oscillations in Ongoing EEG during Major Depression Disorder. Neuroscience Research, 56, 133-144. https://doi.org/10.1016/j.neures.2006.06.006

[98] Morgane, P.J., Galler, J.R. and Mokler, D.J. (2005) A Review of Systems and Networks of the Limbic Forebrain/Limbic Midbrain. Progress in Neurobiology, 75, 143-160. https://doi.org/10.1016/j.pneurobio.2005.01.001

[99] Downer, J.L.d.C. (1961) Changes in Visual Agnostic Functions and Emotional Behaviour Following Unilateral Temporal Pole Damage in the "Split-Brain" Monkey. Nature, 191, 50-51. https://doi.org/10.1038/191050a0

[100] Rosenfeld, J.P. (1995) Alternative Views of Bashore and Rapp's (1993) Alternatives to Traditional Polygraphy: A Critique. Psychological Bulletin, 117, 159-166. https://doi.org/10.1037/0033-2909.117.1.159

[101] James, W. (1884) What Is an Emotion? Mind, 9, 188-205. https://doi.org/10.1093/mind/os-IX.34.188

[102] Shariff, A.F. and Tracy, J.L. (2011) What Are Emotion Expressions for? Current Directions in Psychological Science, 20, 395-399. https://doi.org/10.1177/0963721411424739

[103] Århem, P., et al. (2005) Non-Linear State Transitions in Neural Systems: From Ion Channels to Networks. In: Liljenström, H. and Svedin, U., Eds., Micro- Meso- Macro-: Addressing Complex Systems Couplings, World Scientific Publ. Co., Singapore, 37-72. https://doi.org/10.1142/9789812701404_0004

[104] Mader, S.S. (2000) Human Biology. McGraw-Hill, New York.

[105] Lampe, P.D. and Lau, A.F. (2004) The Effects of Connexin Phosphorylation on Gap Junctional Communication. The International Journal of Biochemistry \& Cell Biology, 36, 1171-1186. https://doi.org/10.1016/S1357-2725(03)00264-4

[106] Aur, D. and Jog, M.S. (2010) Neuroelectrodynamics-Understanding the Brain Language. IOS Press, Amsterdam.

[107] Bal, T. and McCormick, D.A. (1997) Synchronized Oscillations in the Inferior Olive Are Controlled by the Hyperpolarization-Activated Cation Current I h. Journal of Neurophysiology, 77, 3145-3156. https://doi.org/10.1152/jn.1997.77.6.3145

[108] Nunez, P.L. and Srinivasan, R. (1981) Electric Fields of the Brain: The Neurophysics of EEG. Oxford University Press, Oxford.

[109] Schilbach, L., et al. (2008) Minds at Rest? Social Cognition as the Default Mode of Cognizing and Its Putative Relationship to the "Default System" of the Brain. Consciousness and Cognition, 17, 457-467. https://doi.org/10.1016/j.concog.2008.03.013

[110] Nummenmaa, L., et al. (2014) Bodily Maps of Emotions. Proceedings of the National Academy of Sciences, 111, 646-651. https://doi.org/10.1073/pnas.1321664111 
[111] Edelman, G.M. (2004) Wider than the Sky: The Phenomenal Gift of Consciousness. Yale University Press, New Haven. https://doi.org/10.1172/JCI23795

[112] Specker Sullivan, L. (2018) Pure Experience and Disorders of Consciousness. AJOB Neuroscience, 9, 107-114. https://doi.org/10.1080/21507740.2018.1459931

[113] Fingelkurts, A.A. and Fingelkurts, A.A. (2019) Placing Pure Experience of Eastern Tradition into the Neurophysiology of Western Tradition. Cognitive Neurodynamics, 13, 121-123. https://doi.org/10.1007/s11571-018-9506-0

[114] Turner, C.H., et al. (2002) Do Bone Cells Behave Like a Neuronal Network? Calcified Tissue International, 70, 435-442. https://doi.org/10.1007/s00223-001-1024-z

[115] Gundersen, K. (2016) Muscle Memory and a New Cellular Model for Muscle Atrophy and Hypertrophy. The Journal of Experimental Biology, 219, 235-242. https://doi.org/10.1242/jeb.124495

[116] Baluška, F. and Levin, M. (2016) On Having No Head: Cognition throughout Biological Systems. Frontiers in Psychology, 7, 902. https://doi.org/10.3389/fpsyg.2016.00902

[117] Bryan Magee, M.M. (1995) On Blindness: Letters between Bryan Magee and Martin Milligan. Oxford University Press, Oxford.

[118] Koster-Hale, J., Bedny, M. and Saxe, R. (2014) Thinking about Seeing: Perceptual Sources of Knowledge Are Encoded in the Theory of Mind Brain Regions of Sighted and Blind Adults. Cognition, 133, 65-78.

https://doi.org/10.1016/j.cognition.2014.04.006

[119] Doidge, N. (2007) The Brain That Changes Itself: Stories of Personal Triumph from the Frontiers of Brain Science. Viking, New York, 427.

[120] Bova, S.M., et al. (2008) Recovery of Visual Functions after Early Acquired Occipital Damage. Developmental Medicine \& Child Neurology, 50, 311-315.

https://doi.org/10.1111/j.1469-8749.2008.02044.x

[121] Striem-Amit, E. and Amedi, A. (2014) Visual Cortex Extrastriate Body-Selective Area Activation in Congenitally Blind People; Seeing by Using Sounds. Current Biology, 24, 687-692. https://doi.org/10.1016/j.cub.2014.02.010

[122] Evans, R.G. (2007) Plastic Brains. Healthcare Policy, 3, 24-30. https://doi.org/10.12927/hcpol.2007.19169

[123] Saldana, J. (2014) Thinking Qualitatively: Methods of Mind. SAGE Publications, Thousand Oaks.

[124] Kveraga, K., Ghuman, A.S. and Bar, M. (2007) Top-Down Predictions in the Cognitive Brain. Brain and Cognition, 65, 145-168. https://doi.org/10.1016/j.bandc.2007.06.007

[125] Lobo, D., et al. (2013) A Linear-Encoding Model Explains the Variability of the Target Morphology in Regeneration. Journal of the Royal Society, Interface, 11, Article ID: 20130918. https://doi.org/10.1098/rsif.2013.0918

[126] Rosen, M.R. and Cohen, I.S. (2006) Cardiac Memory ... New Insights into Molecular Mechanisms. The Journal of Physiology, 570, 209-218. https://doi.org/10.1113/jphysiol.2005.097873

[127] Prakash, R., et al. (2008) Global Workspace Model of Consciousness and Its Electromagnetic Correlates. Annals of Indian Academy of Neurology, 11, 146-153. https://doi.org/10.4103/0972-2327.42933

[128] Jerath, R. and Beveridge, C. (2019) From Multimodal Phenomena to Peripheral Perception: Sensory Receptors and Top-Down Embodied Cognition. Journal of Neuroscience and Neurosurgery, 2, 129. 
[129] Friston, K. (2005) A Theory of Cortical Responses. Philosophical Transactions of the Royal Society B: Biological Sciences, 360, 815-836. https://doi.org/10.1098/rstb.2005.1622

[130] Rockland, K.S. and Drash, G.W. (1996) Collateralized Divergent Feedback Connections That Target Multiple Cortical Areas. Journal of Comparative Neurology, 373, 529-548. https://doi.org/10.1002/(SICI)1096-9861(19960930)373:4<529::AID-CNE5>3.0.CO;2-3

[131] Purves, D., et al. (2012) Neuroscience. 5th Edition, Sinauer Associates, Sunderland.

[132] Salin, P.A. and Bullier, J. (1995) Corticocortical Connections in the Visual System: Structure and Function. Physiological Reviews, 75, 107-154. https://doi.org/10.1152/physrev.1995.75.1.107

[133] Alvarez, L., et al. (2014) The Computational Sperm Cell. Trends in Cell Biology, 24, 198-207. https://doi.org/10.1016/j.tcb.2013.10.004

[134] Law, R. and Levin, M. (2015) Bioelectric Memory: Modeling Resting Potential Bistability in Amphibian Embryos and Mammalian Cells. Theoretical Biology \& Medical Modelling, 12, 22. https://doi.org/10.1186/s12976-015-0019-9

[135] Bordoni, B., et al. (2018) The Influence of Breathing on the Central Nervous System. Cureus, 10, e2724. https://doi.org/10.7759/cureus.2724

[136] Grossman, L.C.D. and Christensen, L. (2017) On Combat: The Psychology and Physiology of Deadly Conflict in War and in Peace. BookBaby, Pennsauken.

[137] Engel, A.K. and Singer, W. (2001) Temporal Binding and the Neural Correlates of Sensory Awareness. Trends in Cognitive Sciences, 5, 16-25. https://doi.org/10.1016/S1364-6613(00)01568-0

[138] Breit, S., et al. (2018) Vagus Nerve as Modulator of the Brain-Gut Axis in Psychiatric and Inflammatory Disorders. Frontiers in Psychiatry, 9, 44. https://doi.org/10.3389/fpsyt.2018.00044

[139] Edwards, S. (2006) Experiencing the Meaning of Breathing. Indo-Pacific Journal of Phenomenology, 6, 1-13. https://doi.org/10.1080/20797222.2006.11433911

[140] Ramachandran, V.S. and Hirstein, W. (1998) The Perception of Phantom Limbs. The D. O. Hebb Lecture. Brain, 121, 1603-1630. https://doi.org/10.1093/brain/121.9.1603

[141] Jerath, R., Crawford, M.W. and Jensen, M. (2015) Etiology of Phantom Limb Syndrome: Insights from a 3D Default Space Consciousness Model. Medical Hypotheses, 85, 153-159. https://doi.org/10.1016/j.mehy.2015.04.025

[142] Botvinick, M. and Cohen, J. (1998) Rubber Hands "Feel” Touch That Eyes See. Nature, 391, 756. https://doi.org/10.1038/35784

[143] Bai, N. (2018) Yanny vs. Laurel: A Neuroscientist Weighs in. UCSF News Center.

[144] Fingelkurts, A.A., Fingelkurts, A.A. and Kallio-Tamminen, T. (2016) Trait Lasting Alteration of the Brain Default Mode Network in Experienced Meditators and the Experiential Selfhood. Self and Identity, 15, 381-393. https://doi.org/10.1080/15298868.2015.1136351

[145] Gusnard, D.A., et al. (2001) Medial Prefrontal Cortex and Self-Referential Mental Activity: Relation to a Default Mode of Brain Function. Proceedings of the National Academy of Sciences of the United States of America, 98, 4259-4264. https://doi.org/10.1073/pnas.071043098

[146] Philips, R.T., Chhabria, K. and Chakravarthy, V.S. (2016) Vascular Dynamics Aid a Coupled Neurovascular Network Learn Sparse Independent Features: A Computational Model. Frontiers in Neural Circuits, 10, 7. 
https://doi.org/10.3389/fncir.2016.00007

[147] Fingelkurts, A.A., et al. (2016) The Chief Role of Frontal Operational Module of the Brain Default Mode Network in the Potential Recovery of Consciousness from the Vegetative State: A Preliminary Comparison of Three Case Reports. The Open Neuroimaging Journal, 10, 41-51. https://doi.org/10.2174/1874440001610010041

[148] Gusnard, D.A. and Raichle, M.E. (2001) Searching for a Baseline: Functional Imaging and the Resting Human Brain. Nature Reviews Neuroscience, 2, 685-694. https://doi.org/10.1038/35094500

[149] Raichle, M.E., et al. (2001) A Default Mode of Brain Function. Proceedings of the National Academy of Sciences, 98, 676-682. https://doi.org/10.1073/pnas.98.2.676

[150] Lakatos, P. (2005) An Oscillatory Hierarchy Controlling Neuronal Excitability and Stimulus Processing in the Auditory Cortex. Journal of Neurophysiology, 94, 1904-1911. https://doi.org/10.1152/jn.00263.2005

[151] Herrero, J.L., et al. (2018) Breathing above the Brain Stem: Volitional Control and Attentional Modulation in Humans. Journal of Neurophysiology, 119, 145-159.

https://doi.org/10.1152/jn.00551.2017

[152] Buzsaki, G. and Wang, X.J. (2012) Mechanisms of Gamma Oscillations. Annual Review of Neuroscience, 35, 203-225.

https://doi.org/10.1146/annurev-neuro-062111-150444

[153] Canolty, R.T., et al. (2006) High Gamma Power Is Phase-Locked to Theta Oscillations in Human Neocortex. Science, 313, 1626-1628.

https://doi.org/10.1126/science.1128115

[154] Raichle, M.E. (2010) Two Views of Brain Function. Trends in Cognitive Sciences, 14, 180-190. https://doi.org/10.1016/j.tics.2010.01.008

[155] Fernandez-Espejo, D., et al. (2012) A Role for the Default Mode Network in the Bases of Disorders of Consciousness. Annals of Neurology, 72, 335-343.

https://doi.org/10.1002/ana.23635

[156] Panda, R., et al. (2016) Temporal Dynamics of the Default Mode Network Characterize Meditation-Induced Alterations in Consciousness. Frontiers in Human Neuroscience, 10, 372. https://doi.org/10.3389/fnhum.2016.00372

[157] Knyazev, G.G., et al. (2011) The Default Mode Network and EEG Alpha Oscillations: An Independent Component Analysis. Brain Research, 1402, 67-79. https://doi.org/10.1016/j.brainres.2011.05.052

[158] Howard, M.W., et al. (2003) Gamma Oscillations Correlate with Working Memory Load in Humans. Cerebral Cortex, 13, 1369-1374. https://doi.org/10.1093/cercor/bhg084

[159] Popescu, A.T., Popa, D. and Pare, D. (2009) Coherent Gamma Oscillations Couple the Amygdala and Striatum during Learning. Nature Neuroscience, 12, 801-807. http://www.nature.com/neuro/journal/v12/n6/suppinfo/nn.2305_S1.html https://doi.org/10.1038/nn.2305

[160] Baars, B.J. (1993) How Does a Serial, Integrated and Very Limited Stream of Consciousness Emerge from a Nervous System That Is Mostly Unconscious, Distributed, Parallel and of Enormous Capacity? CIBA Foundation Symposium, 174, 282-303. https://doi.org/10.1002/9780470514412.ch14

[161] Sahraie, A., et al. (1997) Pattern of Neuronal Activity Associated with Conscious and Unconscious Processing of Visual Signals. Proceedings of the National Academy of Sciences of the United States of America, 94, 9406-9411.

https://doi.org/10.1073/pnas.94.17.9406 
[162] Morsella, E. and Poehlman, T.A. (2013) The Inevitable Contrast: Conscious vs. Unconscious Processes in Action Control. Frontiers in Psychology, 4, 590. https://doi.org/10.3389/fpsyg.2013.00590

[163] Jiang, J., et al. (2016) Comparing the Neural Correlates of Conscious and Unconscious Conflict Control in a Masked Stroop Priming Task. Frontiers in Human Neuroscience, 10, 297. https://doi.org/10.3389/fnhum.2016.00297

[164] Searle, J.R. (1992) The Rediscovery of the Mind. MIT Press, Cambridge.

[165] Fingelkurts, A.A. and Fingelkurts, A.A. (2005) Mapping of the Brain Operational Architectonics. In: Chen, F.J., Ed., Focus on Brain Mapping Research, Nova Science Publishers Inc., New York, 59-98.

[166] Wilson, A.D. and Golonka, S. (2013) Embodied Cognition Is Not What You Think It Is. Frontiers in Psychology, 4, 58. https://doi.org/10.3389/fpsyg.2013.00058

[167] Favela, L.H. (2014) Radical Embodied Cognitive Neuroscience: Addressing "Grand Challenges" of the Mind Sciences. Frontiers in Human Neuroscience, 8, 796. https://doi.org/10.3389/fnhum.2014.00796

[168] Wilson, M. (2002) Six Views of Embodied Cognition. Psychonomic Bulletin \& Review, 9, 625-636. https://doi.org/10.3758/BF03196322

[169] Foglia, L. and Wilson, R.A. (2013) Embodied Cognition. Wiley Interdisciplinary Reviews. Cognitive Science, 4, 319-325. https://doi.org/10.1002/wcs.1226

[170] Ionescu, T. and Vasc, D. (2014) Embodied Cognition: Challenges for Psychology and Education. Procedia-Social and Behavioral Sciences, 128, 275-280. https://doi.org/10.1016/j.sbspro.2014.03.156

[171] Williams, L.E. and Bargh, J.A. (2008) Experiencing Physical Warmth Promotes Interpersonal Warmth. Science, 322, 606-607. https://doi.org/10.1126/science.1162548

[172] Miles, L.K., Nind, L.K. and Macrae, C.N. (2010) Moving through Time. Psychological Science, 21, 222-223. https://doi.org/10.1177/0956797609359333

[173] Neuhoff, C.C. and Schaefer, C. (2002) Effects of Laughing, Smiling, and Howling on Mood. Psychological Reports, 91, 1079-1080. https://doi.org/10.2466/pr0.2002.91.3f.1079

[174] Kral, A. and Majernik, V. (1996) On Lateral Inhibition in the Auditory System. General Physiology and Biophysics, 15, 109-128.

[175] Roska, B., et al. (2000) Three Levels of Lateral Inhibition: A Space-Time Study of the Retina of the Tiger Salamander. Journal of Neuroscience, 20, 1941-1951. https://doi.org/10.1523/JNEUROSCI.20-05-01941.2000

[176] Heller, M. (2013) Psychology of Touch and Blindness. Taylor and Francis, New York. https://doi.org/10.4324/9781315887555

[177] Yantis, S. (2014) Sensation and Perception. Worth Publishers, New York.

[178] Carpenter, R.H.S. (1997) Neurophysiology. Arnold, London.

[179] Malmivuo, J. and Plonsey, R. (1995) Bioelectromagnetism: Principles and Applications of Bioelectric and Biomagnetic Fields. O.U. Press, Norman. https://doi.org/10.1093/acprof:oso/9780195058239.001.0001

[180] Fingelkurts, A.A. and Fingelkurts, A.A. (2019) Brain Space and Time in Mental Disorders: Paradigm Shift in Biological Psychiatry. The International Journal of Psychiatry in Medicine, 54, 53-63. https://doi.org/10.1177/0091217418791438

[181] Casey, B.J., et al. (2013) DSM-5 and RDoC: Progress in Psychiatry Research? Nature Reviews. Neuroscience, 14, 810-814. https://doi.org/10.1038/nrn3621

[182] Buckner, R.L. and Carroll, D.C. (2007) Self-Projection and the Brain. Trends in 
Cognitive Sciences, 11, 49-57. https://doi.org/10.1016/j.tics.2006.11.004

[183] Cudeiro, J. and Sillito, A.M. (2006) Looking Back: Corticothalamic Feedback and Early Visual Processing. Trends in Neurosciences, 29, 298-306.

https://doi.org/10.1016/j.tins.2006.05.002

[184] Sokoliuk, R. and VanRullen, R. (2013) The Flickering Wheel Illusion: When Alpha Rhythms Make a Static Wheel Flicker. Journal of Neuroscience, 33, 13498-13504. https://doi.org/10.1523/JNEUROSCI.5647-12.2013

[185] Bastos, A.M., et al. (2014) Simultaneous Recordings from the Primary Visual Cortex and Lateral Geniculate Nucleus Reveal Rhythmic Interactions and a Cortical Source for Gamma-Band Oscillations. Journal of Neuroscience, 34, 7639-7644. https://doi.org/10.1523/JNEUROSCI.4216-13.2014

[186] Melnychuk, M.C., et al. (2018) Coupling of Respiration and Attention via the Locus Coeruleus: Effects of Meditation and Pranayama. Psychophysiology, 55, e13091. https://doi.org/10.1111/psyp.13091

[187] Kirmayer, L.J. and Crafa, D. (2014) What Kind of Science for Psychiatry? Frontiers in Human Neuroscience, 8, 435-435. https://doi.org/10.3389/fnhum.2014.00435

[188] Buckholtz, J.W. and Meyer-Lindenberg, A. (2012) Psychopathology and the Human Connectome: Toward a Transdiagnostic Model of Risk for Mental Illness. Neuron, 74, 990-1004. https://doi.org/10.1016/j.neuron.2012.06.002

[189] Walter, H. (2013) The Third Wave of Biological Psychiatry. Frontiers in Psychology, 4, 582-582. https://doi.org/10.3389/fpsyg.2013.00582

[190] Storbeck, J. and Clore, G.L. (2007) On the Interdependence of Cognition and Emotion. Cognition \& Emotion, 21, 1212-1237. https://doi.org/10.1080/02699930701438020

[191] Varga, S. and Heck, D.H. (2017) Rhythms of the Body, Rhythms of the Brain: Respiration, Neural Oscillations, and Embodied Cognition. Consciousness and Cognition, 56, 77-90. https://doi.org/10.1016/j.concog.2017.09.008

[192] Zelano, C., et al. (2016) Nasal Respiration Entrains Human Limbic Oscillations and Modulates Cognitive Function. The Journal of Neuroscience, 36, 12448-12467. https://doi.org/10.1523/JNEUROSCI.2586-16.2016

[193] Damasio, A. and Carvalho, G.B. (2013) The Nature of Feelings: Evolutionary and Neurobiological Origins. Nature Reviews Neuroscience, 14, 143. https://doi.org/10.1038/nrn3403

[194] Heck, D.H., et al. (2016) Cortical Rhythms Are Modulated by Respiration. https://doi.org/10.1101/049007

[195] Lockmann, A.L.V., et al. (2016) A Respiration-Coupled Rhythm in the Rat Hippocampus Independent of Theta and Slow Oscillations. The Journal of Neuroscience, 36, 5338-5352. https://doi.org/10.1523/JNEUROSCI.3452-15.2016

[196] Jerath, R., et al. (2017) The Dynamic Role of Breathing and Cellular Membrane Potentials in the Experience of Consciousness. World Journal of Neuroscience, 7, 66-81. https://doi.org/10.4236/wjns.2017.71007

[197] Li, S. and Laskin, J.J. (2006) Influences of Ventilation on Maximal Isometric Force of the Finger Flexors. Muscle \& Nerve, 34, 651-655. https://doi.org/10.1002/mus.20592

[198] Rassler, B. and Raabe, J. (2003) Co-Ordination of Breathing with Rhythmic Head and Eye Movements and with Passive Turnings of the Body. European Journal of Applied Physiology, 90, 125-130. https://doi.org/10.1007/s00421-003-0876-5

[199] Flexman, J.E., Demaree, R.G. and Simpson, D.D. (1974) Respiratory Phase and 
Visual Signal Detection. Perception \& Psychophysics, 16, 337-339.

https://doi.org/10.3758/BF03203952

[200] Li, S., Park, W. and Borg, A. (2012) Phase-Dependent Respiratory-Motor Interactions in Reaction Time Tasks during Rhythmic Voluntary Breathing. Motor Control, 16, 493-505. https://doi.org/10.1123/mcj.16.4.493

[201] Jerath, R., et al. (2015) Self-Regulation of Breathing as a Primary Treatment for Anxiety. Applied Psychophysiology and Biofeedback, 40, 107-115. https://doi.org/10.1007/s10484-015-9279-8

[202] Kox, M., et al. (2014) Voluntary Activation of the Sympathetic Nervous System and Attenuation of the Innate Immune Response in Humans. Proceedings of the National Academy of Sciences, 111, 7379-7384.

https://doi.org/10.1073/pnas.1322174111

[203] Russo, M.A., Santarelli, D.M. and O’Rourke, D. (2017) The Physiological Effects of Slow Breathing in the Healthy Human. Breathe, 13, 298-309. https://doi.org/10.1183/20734735.009817

[204] Krause, H., et al. (2017) On the Difference of Cardiorespiratory Synchronisation and Coordination. Chaos: An Interdisciplinary Journal of Nonlinear Science, 27, Article ID: 093933. https://doi.org/10.1063/1.4999352

[205] Jerath, R., Barnes, V.A. and Crawford, M.W. (2014) Mind-Body Response and Neurophysiological Changes during Stress and Meditation: Central Role of Homeostasis. Journal of Biological Regulators \& Homeostatic Agents, 28, 545-554.

[206] Zhang, J., Yu, X. and Xie, D. (2010) Effects of Mental Tasks on the Cardiorespiratory Synchronization. Respiratory Physiology \& Neurobiology, 170, 91-95. https://doi.org/10.1016/j.resp.2009.11.003

[207] Fisher, J.P., Young, C.N. and Fadel, P.J. (2009) Central Sympathetic Over-Activity: Maladies and Mechanisms. Autonomic Neuroscience: Basic \& Clinical, 148, 5-15. https://doi.org/10.1016/j.autneu.2009.02.003

[208] Damasio, A.R. (1998) Emotion in the Perspective of an Integrated Nervous System. Brain Research Reviews, 26, 83-86. https://doi.org/10.1016/S0165-0173(97)00064-7

[209] Vuilleumier, P. (2005) How Brains Beware: Neural Mechanisms of Emotional Attention. Trends in Cognitive Sciences, 9, 585-594. https://doi.org/10.1016/j.tics.2005.10.011

[210] Sirota, A., et al. (2003) Communication between Neocortex and Hippocampus during Sleep in Rodents. Proceedings of the National Academy of Sciences, 100, 2065-2069. https://doi.org/10.1073/pnas.0437938100

\section{Abbreviations}

Default Space Theory (DST), Integrated Information Theory (IIT), Operation Architectonics Theory (OAT), Autonomic Nervous System (ANS), Unified Metastable Continuum (UMS), Default Mode Network (DMN), Membrane Potential Oscillation (MPO) 